\title{
New insights into the role of PML in tumour suppression
}

\author{
P Salomoni $^{1}$, BJ Ferguson ${ }^{2}$, AH Wyllie ${ }^{2}$, T Rich ${ }^{3}$ \\ ${ }^{I}$ MRC Toxicology Unit, Lancaster Road Box 138, Leicester, LE 9HN, UK; ${ }^{2}$ Department of Pathology, University of Cambridge, Tennis \\ Court Road, Cambridge CB2 1QP, UK; ${ }^{3}$ Institute of Comparative Medicine, Faculty of Veterinary Medicine, 464 Bearsden Road, \\ Glasgow G61 1QH, Scotland
}

The $P M L$ gene is involved in the $t(15 ; 17)$ translocation of acute promyelocytic leukaemia (APL), which generates the oncogenic fusion protein PML (promyelocytic leukaemia protein)-retinoic acid receptor alpha. The PML protein localises to a subnuclear structure called the PML nuclear domain (PML-ND), of which PML is the essential structural component. In APL, PML-NDs are disrupted, thus implicating these structures in the pathogenesis of this leukaemia. Unexpectedly, recent studies indicate that PML and the PML-ND play a tumour suppressive role in several different types of human neoplasms in addition to APL. Because of PML's extreme versatility and involvement in multiple cellular pathways, understanding the mechanisms underlying its function, and therefore role in tumour suppression, has been a challenging task. In this review, we attempt to critically appraise the more recent advances in this field and propose new avenues of investigation.

Keywords: PML, cancer, PML nuclear body, cell growth, apoptosis, senescence

Cell Research (2008) 18:622-640. doi: 10.1038/cr.2008.58; published online 27 May 2008

\section{Introduction}

The promyelocytic leukaemia protein (PML) has been the subject of intense research for over a decade because of its involvement in acute promyelocytic leukaemia (APL), a subtype of acute myeloid leukaemia (AML). The $P M L$ gene was originally identified through its location at the breakpoint of the $t(15 ; 17)$ translocation that characterises most cases of APL [1]. This translocation is reciprocal and balanced and fuses the $P M L$ gene on chromosome 15 with the retinoic acid receptor alpha (RAR $\alpha)$ gene on chromosome 17 [1]. The result of this is the generation of two fusion genes, $P M L-R A R \alpha$ and $R A R \alpha-P M L$, each encoding a fusion protein $[1,2]$. PML-RAR $\alpha$, which encompasses the majority of the coding regions of the two genes, is the main oncogenic event of APL, while RAR $\alpha$-PML acts as a facilitator in the transformation process [3-6]. RAR $\alpha$ belongs to the nuclear hormone receptor superfamily and activates transcription in the presence of its ligand, retinoic acid (RA) $[1,7]$ to induce many target genes involved in differentiation $[1,7]$. The general view is that PML-RAR $\alpha$ acts a dominant negative mutant for both RAR $\alpha$ and PML, thus leading, respectively, to maturation arrest and inap-

Correspondence: P Salomoni

E-mail: ps90@1e.ac.uk propriate survival $[1,8]$. However, recent data suggest that the picture is more complex and that PML-RAR $\alpha$ can also act as a gain of function mutant [9] (discussed below). Treatment of leukaemic blasts with pharmacological doses of all-trans-retinoic acid (ATRA) results in terminal differentiation and causes remission in patients $[1,10]$. For this reason, APL has become the paradigm of differentiation therapy. Nevertheless, a large number of APL patients acquire resistance to ATRA and undergo relapse $[1,10]$.

Although there are basic aspects of PML biology that remain enigmatic, research in the PML field has moved forward in the last few years, and accumulating evidence suggests that PML has tumour suppressive functions beyond APL in non-haematopoietic tumours.

\section{PML structure}

The human PML gene is expressed as at least 12 (and potentially more) alternatively spliced mRNAs, each of which encodes a distinct protein [11-13]. Each PML isoform shares an identical N-terminal region, consisting of 570 amino acids, encoded by exons 1-6. All nuclear PML isoforms contain a nuclear localisation signal (NLS) in exon 6, and localise both to the nucleoplasm and to a nuclear oncogenic domain (the PML-ND), a large protein complex tethered by high-order PML multimers. The varied nomenclatures used to describe the PML-ND (PML-body, 
PML-NB, POD, ND10) were generated from disparate fields of research and should be considered as interchangeable. There also exist cytoplasmic PML isoforms deficient in exon 6 and, as such, lacking a functional NLS [14]. A single PML isoform, PML-I, also expresses a nuclear export signal (NES), along with its NLS, and hence is able to shuttle between the nucleus and the cytoplasm.

The N-terminal region of PML contains a Really Interesting New Gene (RING), B-box, coiled-coil (RBCC) motif [11], thereby defining PML as a member of the tripartite motif(TRIM) family of proteins [15]. There are more than 60 TRIM family proteins encoded by the human genome, at least five of which are known to be involved in viral restriction (including PML, which is also known as TRIM19), but many others remain functionally uncharacterised [12]. Interestingly, the RING domain is well established as having E3 ligase activity [16] and this activity appears to extend to other TRIM family members [17], although whether all TRIM proteins can act as E3 ligases remains to be ascertained. Coiled coils are well established for their role in oligomerisation [18], but the function of the B-box is less well understood. The recently solved structure of the first human B-box domain revealed a striking similarity with RING domains and suggests a potential role for this domain as an E4 ligase [19]. However, in the context of the RBCC motif, the B-box is known to assist the oligomerisation mediated by the coiled-coil region [20] and so its precise role remains enigmatic. It is known, however, that the RBCC motif as a whole is important for oligomerisation; for example the RBCC motif of the KAP-1 protein has been shown to exist as a trimer in vitro [21]. Also, the spacing, relative to one-another, of the constituent domains of the RBCC motif is precise and highly conserved across the whole TRIM family, suggestive of an important role in defining the overall structure and in coordinating oligomerisation [11]. Indeed, each of these domains is known to be essential for PML-ND formation [22-25]. Despite this knowledge, structural analysis of the PML protein has, thus far, been limited to the individual domains that compose the RBCC motif and there exists only a three-dimensional structure of the isolated RING domain [24]. No structural information is available for any complete RBCC motif or for the exact mechanism of self-association used by the TRIM proteins, which appears so vital for their individual functions.

A further layer of structural and functional complexity is added by small ubiquitin-like modifier (SUMO) modification of PML, which is implicated in multiple aspects of PML function. SUMOylation of PML occurs on three lysine residues (K65 in the RING domain, K160, and K490 in the NLS) [26]. These SUMOylations are critical for the formation of the PML-ND, since PML homo-oligomerises through its RBCC and SUMO-interacting motifs [27], and are critical for the interaction with many PML-ND cargo proteins, including the transcriptional repressor DAXX $[28,29]$. In fact, several members of the RBCC/TRIM protein family act as SUMO, rather than ubiquitin, E3 ligases, and there is some evidence that PML may act in a similar manner [30], possibly mediated by interaction with the SUMO E2 enzyme UBC9 [31]. SUMOylation is a highly dynamic process that is efficiently regulated by the members of the ubiquitin-like protein-specific protease family [32]. Interestingly, PML can be deSUMOylated by the SUMO protease SuPR1 and SUMO proteases in general can affect PML subcellular distribution $[32,33]$. This finding would suggest that PML SUMOylation is also a very dynamic process.

The cellular roles of SUMOylation are multiple and still not fully understood [34], but this modification is known to be important for regulating subcellular localisation and protein complex formation, both of which are also integral to PML function [35]. The intricate and dynamic nature of PML can be highlighted by various observations relating to its SUMOylation. PML can be modified by any of the three SUMO isoforms, 1, 2 and 3 [31, 36, 37]. SUMO 1 modification tends to be monomeric, but recent evidence suggests that in vivo SUMO2/3 oligomers may be covalently linked to PML and that these poly-SUMO chains are integral to PML-ND formation $[32,38]$. It is also known that, whilst the majority of SUMO-1 is constitutively conjugated to its substrates, there exists a free pool of SUMO2/3 that becomes substrate-linked on the receipt of various environmental stresses [39], an observation likely to impact on PML biology.

\section{PML isoforms}

PML function depends on its ability to interact with, hold as cargo or even directly modify various cellular components. This promiscuous protein is best known for its interactions with other nuclear proteins, but it can also form complexes with ssDNA [40,41], specific chromatin sites [41-45], viral genomes [46] and plasmid DNA [47]. PML-NDs have been found associated with many other nuclear organelles or domains such as the nucleolus, telomeres, DNA damage foci and Cajal bodies, and are often described as being attached to the nuclear matrix. This promiscuity, in turn, leads to the association of the PML protein with a wide variety of biological processes, including apoptosis, senescence, protein turnover and the regulation of gene expression.

How, then, is it possible for one protein to have such a wide functionality? Part of the answer to this question lies in the fact that human PML is not really a single protein, but, 
as mentioned above, it exists as a collection of markedly different protein isoforms, each of which may have highly distinct functions. As has been discussed, the N-terminal region governs PML homo-multimerisation, but it is the variable C-terminal region that appears to determine PML's interactions. The $\mathrm{C}$-terminal region of human PML shows remarkable variety across its various isoforms and since murine cells only express two almost identical isoforms this probably represents recent evolutionary diversification. The expression of a limited number of PML splice forms in mice versus multiple variants in higher vertebrates may reflect an ever-specialised role for PML protein in regulating cell stress pathways [48]. The question arises as to whether a driving force for an evolved suite of PML functions has been to overcome the spontaneous transformation events that are so prevalent in murine cells [49]. The standardised nomenclature for the human isoforms is outlined in Figure 1 , which indicates how each protein is spliced from the 13 exons present in the human PML gene. PML isoform 1 (PML-I) has the longest C-terminal region, containing more than 300 amino acids, including an exonuclease (EXOIII) domain, and is the only isoform with an identifiable globular domain outside of the RBCC motif. PML-I is also the most highly expressed [48] and probably the oldest isoform, sharing the highest homology with the murine isoforms. It is probable, therefore, that PML-I plays a key structural role in PML-ND formation, but the presence of the EXOIII domain suggests that this isoform may also be important for chromatin tethering and remodelling and for interactions with nucleic acid [41, 47]. Indeed, one specific role of PML is in the direct control of gene expression through associations with particular gene loci such as the MHC gene locus $[45,50]$. Apart from the EXOIII domain, the remainder of the PML-I C-terminus is predicted to be unstructured, a common theme amongst the other PML isoforms also (Figure 2). The identification of such unstructured regions in the PML protein is consistent with the promiscuity of its interactions. It is becoming established that natively unstructured or disordered regions are common amongst proteins involved in protein/protein and protein/DNA interactions. It is estimated that $40 \%$ of proteins encoded by the human genome contain such regions and this percentage is higher amongst proteins implicated in transcriptional regulation and cell signalling pathways [51]. Structural flexibility provides several advantages to protein interactions, all of which can be applied to PML functionality. For example, disordered polypeptides interact with faster kinetics and with a wider range of binding partners than rigid, globular protein domains [51], and these represent traits that are clearly advantageous to PML.

In support of the idea that individual isoforms have distinct roles, there is growing evidence for isoform-specific protein/protein interactions. PML-II, for example, is known to interact specifically with the adenoviral E4 Orf3 protein [52], whilst PML-IV [53, 54] has been claimed to interact specifically with p53. PML-IV also interacts with

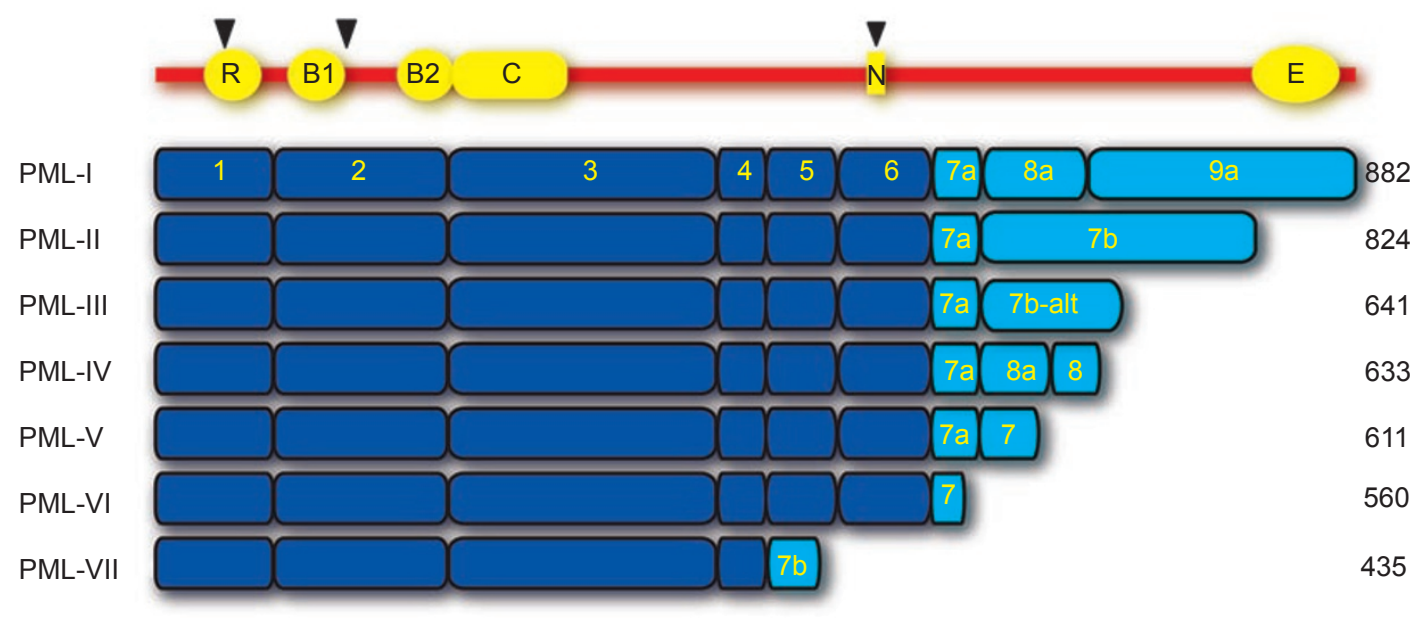

Figure 1 Human cells express a repertoire of PML isoforms. PML protein comprises a set of six nuclear isoforms I-VI encoded by a single gene via alternative RNA splicing. The generalised domain structure is shown (top), indicating positions of the Ring domain ( $\mathrm{R}$ - amino-acid residues 45-105), Beta box 1 (B1 - residues 124-166), Beta box 2 (B2 - residues 184-230), Coiledcoil $(C$ - residues 229-323) and Exonuclease domain ( $E$ - residues $\sim 600-750$, exclusive to isoform I). Positions of the nuclear localisation sequence $(\mathrm{N})$ and SUMOylation sites (black arrowheads) are also indicated. The lower panel indicates exon usage for the PML isoforms. Exons 1-6 (dark blue) are common to all nuclear isoforms, the variability in their C-termini being encoded by several alternatively spliced exons as indicated (light blue). The omission of exon 6, which carries the nuclear localisation signal, generates cytoplasmic PML (isoform VII). 
PML isoform disorder prediction

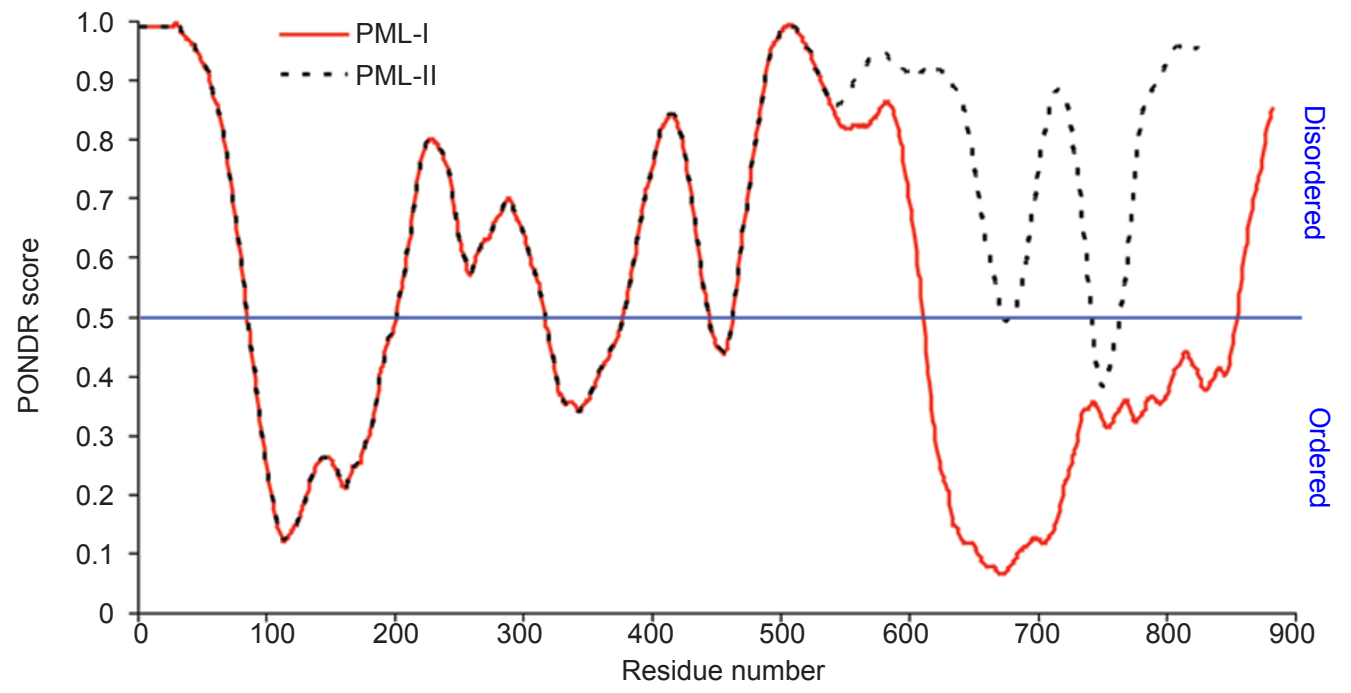

Figure 2 PML isoforms display differential propensities for structural order at their C termini. The PONDR algorithm (http://www. pondr.com/pondr-tut2.html) uses a neural network predictor trained to identify naturally disordered regions in proteins. PONDR is the acronym for 'Predictor Of Naturally Disordered Regions'. PONDR scores below the boundary (0.5) signify a propensity for order, with scores above 0.5 indicating a high likelihood of disorder. The PONDR VL3 disorder prediction for PML isoforms I and II is shown. Extensive regions of disorder occur throughout the C-terminus of PML-II, whereas PML-I has a structured C-terminal region which corresponds to the EXOIII domain.

hypophosphorylated retinoblastoma protein (pRb) [55] and the histone deacetylases (HDACs) [56] and it is through such interactions that PML-IV has also been implicated in specific cellular processes such as the induction of senescence [57]. The C-terminus of PML-I was recently shown to be responsible for its interaction with the nucleolus [58] although the precise specificity and function of this interaction are unknown. Cytoplasmic PML isoforms, meanwhile, have been implicated in TGF $\beta$ signalling through direct interactions with the SMAD2 and SARA proteins [59].

These observations underlie several crucial and unanswered questions in PML biology, which must be addressed in order to correctly understand this system. Although it is now known that multiple PML isoforms must accumulate to create a single, functional PML-ND [48], it is not known whether PML's activities are associated with its presence in the nucleoplasm or at the nuclear domain. It is possible, for example, that the PML-ND acts merely as an inert storage site for inactive cargo proteins, such as DAXX, which can be shuttled in and out of the domain, probably by specific PML isoforms, as and when required [56, 60]. This model might explain why PML bodies can be found juxtaposed to other nuclear domains, such as DNA damage foci. Here, signalling proteins such as $\mathrm{CHK} 2$, which is known to be modified by ATM at the site of double-strand breaks and then further modified at the PML-ND [61, 62], may be ef- ficiently shared between the two sites. However, PML's role in DNA and chromatin interactions appears to be centred inside the nuclear domain itself as it is here that quiescent viral genomes, ssDNA and telomeres are found [40, 46, 63-65]. These considerations lead to an alternative model, in which the PML-ND provides a microenvironment that fosters specific activities in the proteins with which it associates.

It is also apparent that PML functions differently and interacts with different partners in different cell lines, or even within the same cell population at different times. In ALT cells, for example, PML associates with telomere foci [64], whilst in senescent cells it often rings the nucleolus [58]. Studies of relative levels of PML-I RNA in various tissues, tumours and cell lines indicated a diverse level of expression for this isoform [48]. The loss of PML-I expression (as well as the loss of PML expression in general) is often associated with transformation [66]. It thus seems likely that isoform expression levels titrate PML function in different cell environments, including the adaptive response to various types of cell stress. Similarly, the intracellular localisation of PML varies between cell lines. The majority of PML in human diploid fibroblasts, for example, lies within PML bodies, whereas various transformed cell lines, such as HCT116 and HEK293, appear to contain a greater pool of nucleoplasmic PML (BF, TR, unpublished 
observations).

\section{The PML network}

PML functionality, although enigmatic, remains intrinsically linked to its interactions with other cellular macromolecules. The detection of a wide range of cellular stresses alters the expression, modification and localisation of PML, which, in turn, alters its capacity for interaction. All of these factors combine to determine the function of PML.

In order to understand the function of PML, it is therefore essential to characterise its interactions both before and following specific stresses. So far attempts to do so have been hampered by weak-binding antibodies and by PML's dynamic nature, which results in rapid deSUMOylation following cell lysis [67]. Despite this, the identification of several mitogenic signalling proteins as novel PML interacting partners has helped to underline PML's role in growth and tumour suppression. Akt, mTOR (the target of rapamycin protein) and PLC $\gamma$ [68-70] have all been recently identified as PML binding partners. Thus, as will be discussed later, PML has been shown to be a member of a signalling network, negatively regulating the nuclear content of pAkt via dephosphorylation by PP2A, and hence supporting the accumulation of nuclear FOXO3A and the resulting transcription of the cell cycle inhibitor $\mathrm{p} 27^{\mathrm{Kip}}$ and the pro-apoptotic factor Bim [70]. The modulation of such signalling pathways is a novel aspect of PML biology, but fits well with the paradigm that PML, or PML bodies, provides the micro-environment for many varieties of protein modifications and so regulates a wide spectrum of cellular behaviour.

\section{The PML-ND}

The PML-ND is still something of terra incognita on the cell biology map. We do not yet have a blueprint for how or where in the nucleus to construct PML-NDs. On top of this, heterogeneity of PML-ND morphology and composition can exist within the same cell nucleus, which may be driven by contributions from different PML isoforms. From a biochemical perspective, the fabric of the PML-ND is SUMOylated PML, which imparts an exquisite sensitivity to cell injury. Stress deforms, fragments and disperses the PML-ND, sending its cargo proteins to varying fates that provide little chance of capturing their peptide signatures by classic biochemistry. PML-ND modifications appear to be driven by stresses that can sever the chromatin fibres that anchor PML-NDs to the matrix, as well as by activated injury response pathways that alter PML's phosphorylation or SUMOylation status [67]. The technical challenge posed by the frailty of PML-NDs has often been sidestepped by analysing more robust ectopic species. This approach revealed that all nuclear isoforms of PML, including a non-SUMOylatable mutant, could form homotypic PML-NDs [28]. A significant drawback to these experiments, however, was the realisation that ectopic human PML-NDs do not resemble their endogenous counterparts in size, stress sensitivity nor even, in many cases, morphology $[71,72]$. Even the authenticity of an ectopic murine PML-ND is suspect given that nucleoplasmic PML is often drawn into the PML-ND, thereby skewing its molecular composition. This composition may be critical if macromolecular crowding plays any part in driving PML's effector functions [73]. Despite these caveats, mass spectrometry of PML co-immunoprecipitates has been used to identify PML partners and ND cargo proteins, one of which was PLC $\gamma-1$ [69]. This discovery is noteworthy given that PLC $\gamma-1$ shares a substrate $\left(\mathrm{PIP}_{2}\right)$ with PI3K, an upstream activator of pAkt. The identification of both Akt and PLC $\gamma-1$, bound to PML, illustrates the potency of PML and PML-NDs in intervening in multiple pathways involved in cellular homeostasis. This finding also illustrates the variety of lipid metabolising proteins that have been found in the nucleus, many with roles autonomous to those played out in the cytoplasm [74].

A significant conceptual advance in our understanding of PML-ND formation came with the identification of a SUMO interacting motif(SIM) in the PML protein. PML's SIM, together with its RING domain, is critical for PMLND formation [27] and provides a mechanism to interweave SUMO modified PML and third party SUMOylated proteins. Within this higher-order PML structure other scaffold proteins are found. Thus, the transcriptional repressor DAXX uses a SIM to tether and silence SUMOylated transcription factors at PML-NDs [29]. These data reveal a hierarchy of signalling nodes, each providing a niche to drive or repress effector functions. A simplistic mechanism to compartmentalise repressive and activating PML-ND chaperone functions could be to partition these functions to the inner and outer surfaces of the domain, respectively. Exceptions to this segregation almost certainly occur, and may include the oncogene-driven acetylation of p53 [75]. The discovery of SUMO proteases targeting SUMOylated PML and the PML-NDs has added a further level of complexity $[32,33]$. It is therefore plausible that changes in PML-ND composition or structure could be controlled by the balance between SUMOylation and deSUMOylation of PML and other PML-ND constituents. This area of research awaits further investigation.

\section{PML-ND alteration by stress}

Several endogenous and exogenous types of stress have been shown to alter PML-NDs. These observations led to 
experiments that attempted to link cell fate with PML-ND morphology. Initially the emphasis was on using sources of exogenous stress to promote PML-ND modification; more recently PML-ND modification by endogenous stress has also been recognised [67]. Varying levels of endogenous stress may explain the regular and abundant PML-NDs that typify early passage fibroblasts [72] versus the low numbers of fragmented PML-NDs that typify many cancer cell lines. Collectively, data accrued for PML-ND function after stress recognition point to a protective homeostatic role. It is therefore not surprising that PML-ND distribution and composition following differing challenges reflect these variables. In telomerase negative cancer cells, for example, the imperative to maintain telomeres by recombination is supported by a subset of PML-NDs (in this case called ALT bodies - see sections below). Likewise, clastosomes, rich in ubiquitin conjugates and proteasome subunits, are PML-NDs that metabolise misfolded proteins [76].

The responses of PML-NDs to different types of DNA damage illustrate some of the complexities of PML-ND function. The activation of the ATM-CHK2 and ATR pathways following ionising radiation plays an important role in the reorganisation of PML-NDs after genotoxic damage $[72,77]$. Activated ATR also regulates a different stress signal that controls MDM2 sequestration by PML at the nucleolus [78]. The demonstration that caspase-2 can also reside within PML-NDs [79] has led to the fresh speculation that this initiator caspase is part of a nuclear apoptosome at the PML-ND [80]. Though the finding that Sp100 also contains a CARD domain may be taken as supporting evidence of this [81], it is equally likely that caspase-2 is sequestered in the PML-ND and that Sp100 plays some part in this sequestration. Note that caspase- 2 is ordinarily expressed at the Golgi, and stimuli that would cause its re-localisation to PML-NDs have yet to be identified. The striking juxtaposition of PML-NDs with irradiation induced foci (IRIF), together with the delayed timing of this event and its relationship to the delivered radiation dose, may point to a role for PML in the auditing of DNA damage prior to selecting cell fate [72], or to its participation in chromatin modification. A precedent for PML-ND function in chromatin regulation has been provided by patients with centromeric instability and facial dysmorphy (ICF) syndrome, which is caused by defective DNA methylation $[41,44]$. The expression of the EXOIII domain in PML-I may even be a relic of PML activity in metabolising nucleic acid, though it is likely that this function has now been lost [58].

Different types of genotoxic stress affect the PML-NDs differently. For instance, upon UV irradiation or cisplatin treatment PML-NDs dramatically reorganise into microspeckles, where the transcription factor c-Jun accumulates
$[8,82,83]$. Unlike ionising radiation, UV damage tends to elicit a response mediated by ATR, which promotes MDM2 sequestration by PML at the nucleolus [78]. Overall, these findings suggest that PML-NDs have a close relationship with the DNA damage machinery and may integrate DNA damage signals with other stress signals (e.g. through c-Jun). Microspeckle formation contrasts with the PML response to other stresses such as heat shock and viral infection. Heat shock also reorganises PML, but by an almost instantaneous deSUMOylation event which, if prolonged, disperses PML along with SP100 and DAXX [84].

Studies from the fields of neurodegeneration and virology have also illuminated different aspects of PML-ND function. There is an extensive literature showing PML-ND disruption by protein aggregates and viruses. Collectively these data show that, in general, PML-NDs detect unusual cellular events, including unscheduled accumulations of proteins (aggregates or viral capsids) or nucleic acids (naked viral material, open chromatin or plasmid DNA). Interestingly, exposure to interferon, which is part of the cellular response to viral infection, greatly enhances PML expression and results in increased numbers of enlarged PML bodies and, depending on the interferon used, higher levels of nucleoplasmic protein $[85,86]$. The question remains as to how PML-NDs perceive protein aggregates or nucleic acids. Elegant experiments from the Everett laboratory have shown that PML-NDs readily detect the ingress of virus and that PML protein re-localises to the site of viral entry [87]. Experiments based on fluorescence recovery after photo-bleaching demonstrate the rapid exchange of PML protein between matrix-bound PML-NDs and the nucleoplasm and may point to a mechanism for stress detection [87]. PML shuttling between compartments may serve to alert the PML-ND as to local concentrations of protein and nucleic acid, and these transitions may be accelerated by the detection of pathogen-associated molecular patterns (PAMPs) or the activation of injury recognition pathways.

In the case of protein folding diseases, nuclear inclusions of aggregated protein rapidly recruit PML-NDs [88] and in some circumstances may seed within PML-NDs, eventually rupturing the domain [89]. Whilst the propensity for PML-NDs to detect and sequester ectopic protein often leads to the false positive designation of cargo proteins, this intrinsic property of PML clearly demonstrates its important homeostatic function. Interestingly, in vitro reconstruction of the genesis of aggregates of ataxin-1 within nuclei demonstrated not only the avidity of PMLNDs for these aggregates, but also that PML-NDs bound to the aggregates completely lost their capacity to respond to other stress stimuli such as heat shock or ionising radiation [90]. This observation thus adds defective PML-ND 
function to the list of mechanisms that might be ultimately responsible for the neuronal cytotoxicity associated with protein aggregate diseases.

\section{Biologic functions suggested by PML-ND modifica- tion}

PML-NDs have, by virtue of their modifications after stress, given tantalising clues as to their biologic role, though the observational nature of these data has often led to their neglect. Thus, ten years ago it was reported that senescent fibroblasts express unusually large fibrillar PML-NDs [91], but only recently has it been shown that enlarged PML-NDs in senescent cells can sequester nucleolar proteins $[58,92]$ and that the $\mathrm{C}$ terminus of PML-I and its EXOIII domain, promote the stress-induced nucleolar redistribution of PML [58]. The degradation of PML-I by excessive casein kinase II activity in cancer cells would disrupt this homeostatic function and could exacerbate cellular injury [93] (see below). It is now clear that PML can be distributed within cells in several patterns other than classical PML-NDs, potentially causing, or reflecting, different biological and pathological functions.

\section{PML and the nucleolus}

The link between nucleoli and PML-NDs is a fascinating one. In an early report, PML and PML-ND cargo proteins were seen to translocate to the nucleolus in cells treated with proteasome inhibitors [94]. We noted that PML may re-localise to the area of chromatin immediately surrounding the nucleolus after the delivery of other stresses including heat shock or IR. The role of this translocation is unknown though several possibilities exist. Proteome analyses of the nucleolus have revealed a surprisingly large number of DNA repair and tumour suppressor proteins [95]. Many of these are mobilised both into and out of the nucleolus after stress which may accompany the partitioning of nucleolar compartments [96]. Condemine [58] proposed that PML-NDs actively involved in proteolytic regulation are recruited to nucleoli. PML translocation to the periphery of the nucleolus may also deliver effectors that repress ribosome biogenesis, as part of cellular shutdown. Alternatively, the perinucleolar expression of PML may signify repairs to nucleolar DNA.

\section{PML-NDs and fibril tracks}

One of the principal un-explored observations of PMLND function is 'tracking' of PML fibrils: sinuous threads decorated with PML microbodies that can extend the length of the nucleus (Figure 3). In our hands (TR, unpublished observations), the most prominent examples of tracking have been seen in senescent diploid fibroblasts. The existence of a fibrillar nuclear matrix is contentious [97] though elegant descriptions of aberrant matrices in cancer cells would suggest that a normal matrix exists and supports a tumour suppressive function [98]. The extent to which domains of PML-NDs would traverse the matrix tethered to fibrils is open to debate. The dispersal of monomeric or oligomeric PML from PML-NDs into the nucleoplasm shows none of the linearity that would be expected of protein traversing a fibrillar network. Though mobile domains of PML have been reported, their movement may have reflected the action of Sp100 protein rather than PML [99]. Of relevance to our observations of tracks in senescent cells are the ubiquitin bridges described by Condemine [58], which are especially prominent in cells treated with proteasome inhibitors. These ubiquitin bridges resemble the 'comets' of PML that we have seen between PML-NDs and polyglutamine aggregates [100]. As proteasome inhibition can arise in cells expressing polyglutamine proteins as well as in senescent cells (discussed later) [101], we could suggest that a directionality for PML and PML-ND movement may be provided by concentration gradients of ubiquitinated substrates. The possibility that both poly-ubiquitin and PML attach to a shared structure in the nuclear matrix has been made [58]. Perhaps this arrangement would allow
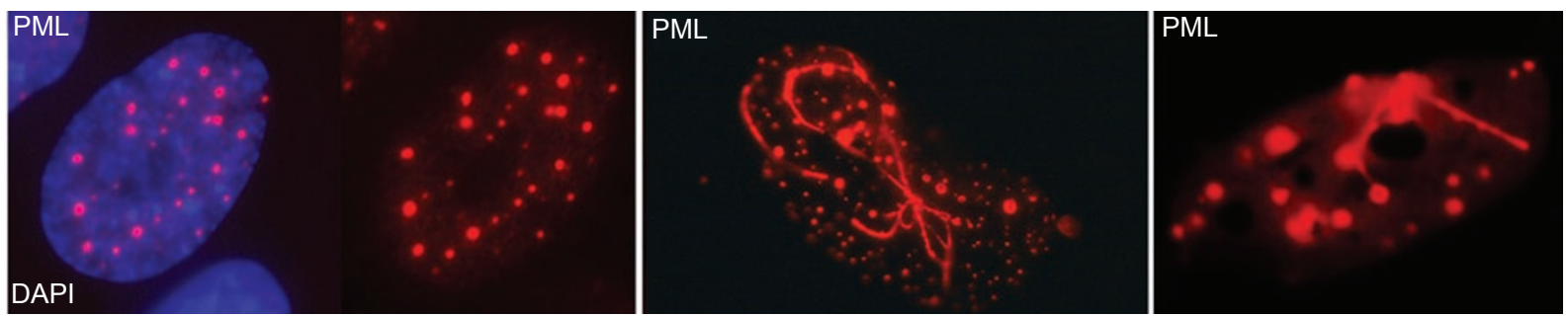

Figure 3 PML tracking in senescent fibroblasts. Immunofluorescence in actively growing normal diploid human fibroblasts (left panel) exhibits the standard, punctate PML staining common to many cell types both in vitro and in vivo. Following the transition to senescence achieved by degradation of the SV40 large T antigen, and without recourse to proteasome inhibitors, these cells reveal endogenous PML tracks (right panels). 
PML protein to monitor the contents of the interchromosomal space in a fashion analogous to another TRIM protein in the cytoplasm, TRIM5 $\alpha$ [102]. One constant in the study of PML-NDs is that the observation of atypical distributions of these domains, in uninfected cells, has led to significant discoveries concerning stress pathways and homeostasis. To overlook PML-ND distribution is to lose a critical clue as to the prevailing effector functions active in each cell.

\section{PML and the centrosome}

Several lines of evidence suggest that PML isoforms can have specialised functions. In particular, a recent report demonstrated a role for PML-III in centrosome duplication and genome stability [103]. $\mathrm{P}^{l^{\prime-}}$ MEFs were shown to have amplified centrosomes in more than $35 \%$ of cells examined. In normal cells centrosome duplication occurs in the G1/S phase of the cell cycle. In primary and immortalised MEFs lacking PML, the mechanism that regulates centrosome reduplication is impaired, allowing unscheduled duplication in the absence of DNA replication. Isoform-specific siRNAs were then used to demonstrate that PML-III was the isoform responsible for the control of this cellular process. Furthermore, PML-III was shown to bind to and inhibit Aurora A, a serine/threonine protein kinase associated with the centrosome and implicated in the regulation of mitotic microtubules and centrosome maturation [103]. Interestingly, co-localisation of PMLIII and $\gamma$-tubulin (a central component of the centrosome) was not impaired in APL cells, as shown using a PML-III specific antibody. This indicated that, although other PML isoforms form heterodimers with PML-RAR $\alpha$ and become diffusely distributed in the nucleus of APL blasts, PML-III apparently retains its normal functions through its interaction with the centrosome in the cytoplasm [103]. Aurora A phosphorylates and destabilises p53 [104], hence inhibiting the transcription of p21 and so permitting activation of the $\mathrm{Cdk} 2 /$ cyclin E complex, which is essential for regulating centrosome duplication. Taken together, these data suggest that PML-III controls centrosome duplication by regulating Aurora A activation, a potent demonstration of PML isoform-specific function in genomic stability. These conclusions have recently been challenged, as colocalisation of PML-III with the centrosome was not observed in Chinese hamster ovary cells or $\mathrm{Pml}^{H_{-}^{-}}$MEFs that stably expressed PML-III, or in HeLa cells, MRC5 primary human fibroblasts, the APL-derived cell line NB4 or APL primary cells [48]. Discrepancies between the two studies may be explained by the use of different antibodies or immunofluorescence conditions. Clearly, PML localisation to centrosomes needs reassessment.

\section{Cytoplasmic accumulation of PML}

Whilst the nuclear function of PML has been the focus of much research in the past decade, several lines of evidence suggest that PML plays additional roles in the cytoplasm. As mentioned above, splice variants of PML localise to the cytoplasm and PML isoform I contains a functional NES [11, 58]. Interestingly, cytoplasmic PML isoforms are induced by TGF $\beta$ and mediate its growth suppressive functions [59, 83] (extensively discussed in [14]). During the cell cycle, the number and shape of PML-NDs are dramatically altered at the $\mathrm{S}$ and $\mathrm{M}$ phases [105-108]. In particular, during mitosis, PML re-distributes to cytoplasmic structures called mitotic accumulation of PML proteins (MAPPs), which are retained in the cytoplasm in early G1 phase [77, 109]. MAPPs have been proposed to regulate the nuclear formation of PML-NDs after mitosis [109]. Overall, these findings suggest that the balance between nuclear and cytoplasmic PML could be involved in regulating its tumour suppressive functions. Indeed, cytoplasmic accumulation of PML has been found in human neoplasia, such as in APL and skin tumours due to mutation or other mechanisms, thus suggesting it could play a role in tumorigenesis $[58,66]$ (see the paragraphs below).

\section{PML tumour suppressive functions}

Although the tumour suppressive role of PML was immediately suggested by the identification of the RAR $\alpha$ fusion protein in APL, clear evidence for its mechanism has emerged more slowly. PML has been shown to interact and co-localise with a very large number of proteins, but the physiological role of many of these interactions remains unproven as they have been observed only under conditions of enforced expression of ectopic PML. Also, many such interactions have not been shown to be relevant for tumour suppression. Here we focus only on PML interacting partners and regulated pathways with a clear role in oncogenesis.

\section{Cell cycle and cellular senescence}

Cellular replicative senescence is a permanent exclusion from the cell cycle. It is considered to be one of the main barriers against tumorigenesis, and there is good evidence that it is caused by induction of the DNA damage response [110-112]. Most data on the induction and regulation of senescence have been obtained using cell culture systems [110-112] and, more often than not, study damage-induced senescence that may still be reversible. The term 'senescence' seems to be applied to a vast number of disparate cell states and this usage, as well as the absolute assumption of a G1 arrest, is problematic. However, senescence-associated markers have also been demonstrated in vivo in normal 
tissues and in pre-neoplastic lesions, thus suggesting that senescence can occur in vivo and is activated in the early phases of tumorigenesis [110-112]. Depending on the cell type, it requires activation of p53 alone or both p53 and $\mathrm{pRb}[112,113]$ and it can be initiated by inappropriate activation of oncogenes. Several studies have clearly shown that overexpression of PML induces cell cycle arrest in cancer cell lines [114-116]. This was associated with increased levels of $\mathrm{pRb}$, and an arrested cell cycle, principally at the G1 phase [116-118]. Interestingly, PML potentiates the repressive function of $\mathrm{pRb}$ [119]. Moreover, endogenous PML expression is augmented both in G1 arrested cells and when p53 is over-expressed [116]. More recently, it has been shown that expression of the PML-IV isoform induces replicative senescence in primary human and mouse fibroblasts $[57,120]$. This requires endogenous PML [57] though, perhaps surprisingly, not the PML-ND [57]. In human fibroblasts, $\mathrm{pRb}$, but not $\mathrm{p} 53$, is required for PML-IV-induced senescence [120].

One of the problems associated with PML over-expression studies is that PML tends to form high molecular weight aggregates that could have non-specific effects on the cell cycle. For this reason Pml-/- cells and mice represent a better model with which to study PML function [121]. Knockout of PML results in increased proliferation in mouse embryonic fibroblasts and a reduced sensitivity to the growth suppressive effects of RA [121, 122]. PML is also required for senescence induced by expression of the mutated G12V H-ras oncogene and modulates p53 activation through acetylation in a CBP-dependent mechanism [75] (Figure 4). This acetylation is inhibited by PML-RAR $\alpha$ because of its dominant negative effect on PML [123].
Interestingly, PML is induced by p53 activation [124] and is a target of p53, suggesting the existence of a positive feedback that may lock affected cells into permanent replicative arrest [125]. Both in humans and mouse, PML interacts with and colocalises with $\mathrm{pRb}[119,120,126]$, but the non-murine isoform, PML-IV, induces a senescence which is pRb dependent [120] (Figure 4). PML over-expression results in the accumulation of hypophosphorylated $\mathrm{pRb}$ [116-118] and potentiates $\mathrm{pRb}$ function through a HDAC-dependent mechanism [119]. Finally, PML-RAR $\alpha$ blocks $\mathrm{pRb}$ function, thus suggesting that the inactivation of $\mathrm{pRb}$ may be involved in APL pathogenesis [119]. These findings demonstrate that PML is involved in the induction of cellular senescence, and that this is achieved through regulation of the tumour suppressors, $\mathrm{pRb}$ and $\mathrm{p} 53$. It remains to be addressed how PML action is directed towards either tumour suppressive pathway.

Recent studies have added a further level of complexity by proposing that PML-NDs are involved in chromatin reorganisation during senescence [127-129]. The senescent phenotype necessitates the formation of specialised domains associated with transcriptionally silent chromatin. These domains, called senescence associated heterochromatic foci (SAHF), are thought to repress the expression of genes involved in cell cycle progression [130]. Interestingly, a number of E2F target genes acquire heterochromatic features during senescence, and active $\mathrm{pRb}$ binds their promoters [130]. Furthermore, $\mathrm{pRb}$ is required for SAHF formation and the repression of E2F target genes during senescence [130]. Both SAHF and PML-NDs are induced during cellular senescence. The temporal and physical relationship between the two structures has been,

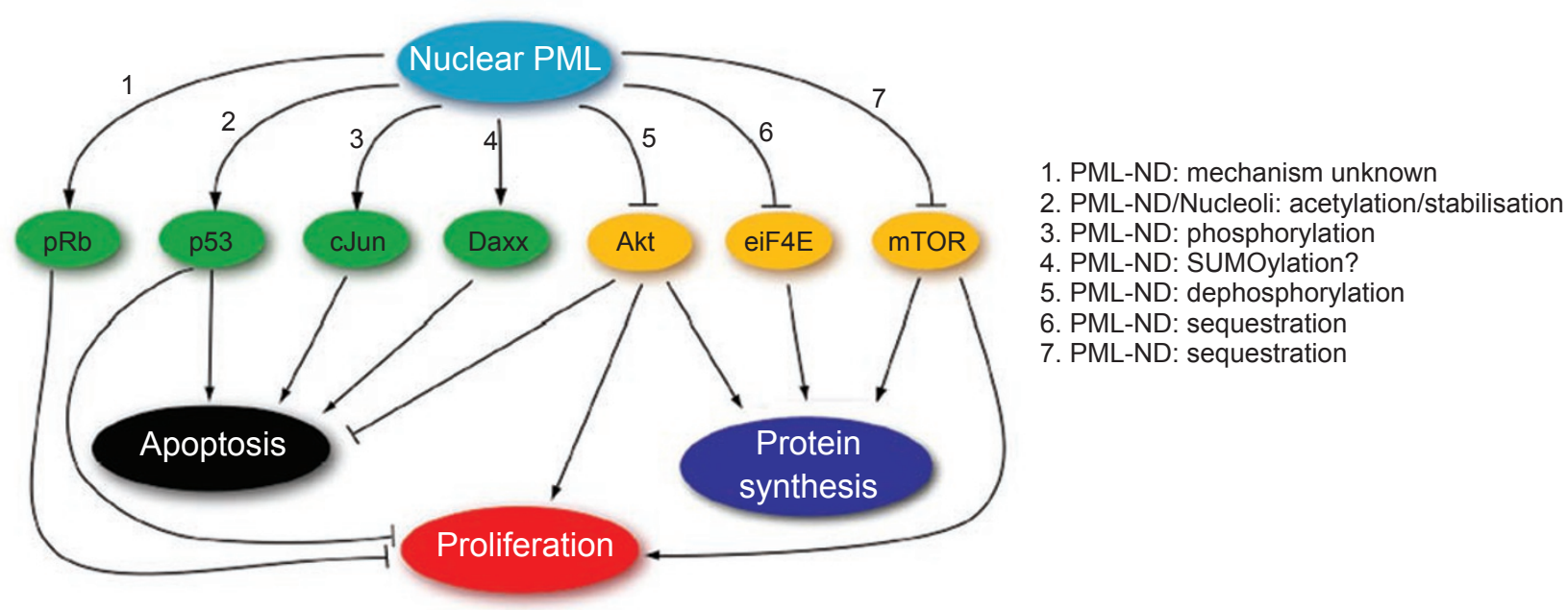

Figure 4 PML interacting proteins and their roles in tumorigenesis. PML can activate several tumour suppressors and inhibit oncogenic pathways. Boxed in green are proteins with tumour suppression activity, while proteins boxed in yellow positively affect metabolism/proliferation and inhibit cell death. The text summarises current knowledge of the underlying mechanisms. 
in part, elucidated by the work of Peter Adams' laboratory $[127,128,131]$. These studies showed that, prior to SAHF formation, a known chromatin regulator, HIRA, enters PML-NDs and transiently colocalises with heterochromatin-1 (HP1) proteins, which are involved in the formation of heterochromatin. Disruption of either HIRA or PML function results in impaired SAHF formation, thus suggesting that transient accumulation of HP1 in PML-NDs is required for SAHF generation [127]. As mentioned above, the modified PML-NDs found in the centromeric ICF syndrome also contain multiple HP1 isoforms, in addition to the chromatin remodelling $\alpha$-thalassemia/mental retardation X-linked syndrome (ATRX) protein [41, 44]. The identification of giant PML-NDs in ICF cells at the G2 phase of the cell cycle has been used to propose a model for PML-ND function in the epigenetic control of chromatin during cell cycle [41]. A similar role could be proposed for chromatin modelling during senescence.

One possible mechanism for these changes in chromatin would be that chromatin modifiers undergo post-translational modifications as they transit through PML-NDs or ICF bodies, which are in turn required for SAHF formation. In this respect, phosphorylation of one of the HP1 proteins, HP $1 \gamma$, is known to be required for its localisation to SAHF but not to PML-NDs, a circumstance easily explained if its phosphorylation occurs in PML-NDs to promote its loading into SAHF [131]. Perhaps the colocalisation of $\mathrm{pRb}$ in the PML-NDs of senescent cells $[118,120]$ also permits the post-translational modifications necessary for the repression of E2F release and subsequent chromatin alteration. Overall, these findings support the notion that PML-NDs are credible candidate sites for the modification of tumour suppressors and other proteins involved in senescence.

\section{Apoptosis}

Pml and p53 In addition to the inhibition of cell cycle, several tumour suppressors initiate apoptosis, and there is good evidence that PML also activates this process. Thus, PML over-expression induces apoptosis by a process blocked by the pan-caspase inhibitor zVAD [132], and splenic lymphocytes and thymocytes from Pml-/- mice show barely half the capacity of wild-type cells to initiate apoptosis. It is notable that this applies to apoptosis induced by both ionising radiation (a stimulus whose lethality depends largely on p53 in these cell types) [54, 133, 134] and the cytokine death-receptor pathway [135]. These observations suggest that the modulation of apoptosis by PML affects a step in the apoptosis effector pathway that is common to both stimuli. At present it is far from clear what this might be. More recent studies have proposed that PML-dependent $\mathrm{p} 53$ regulation during apoptosis is multifaceted. For instance, PML can regulate p53 degradation through the inhibition of Mdm2, which is the major p53 E3 ubiquitin ligase [78, 136-140] (Figure 4). In particular, PML has been shown to co-localise with and sequester $\mathrm{Mdm} 2$ into nucleoli, thus promoting p53 activation upon DNA damage [78].

Overall, the evidence presented in this and the previous section suggests that PML can activate $\mathrm{p} 53$ by different means, acetylation and stabilisation. However, it is not clear what triggers either of the two mechanisms. It could be hypothesised, for example, that different PML isoforms could exert different functions. In this respect, PML-IV is the main isoform able to interact with p53, but it is not clear whether a specific isoform is required to sequester $\mathrm{Mdm} 2$ to nucleoli. As different types of DNA damaging agents have been used in the papers discussed above, it is plausible that specific isoforms could be induced or activated depending on the stimulus used. For instance, PML-I contains a nucleolar localisation sequence that promotes its accumulation into nucleoli upon stress and cellular senescence [58]. It remains to be determined whether PML-I is required for p53 stabilisation upon cellular stress.

Additional mechanisms Another PML-ND component is DAXX, a protein originally cloned as a CD95-associated factor [141-143]. However, the cytoplasmic localisation of endogenous DAXX and its association with CD95 are not clear and more recent studies have doubted the relevance of this association for the induction of cell death ([144] and references cited therein). The requirement of PML for DAXX-induced cell death suggests the existence of a novel nuclear complex for apoptosis induction [144] (Figure 4). Possible mechanisms, for which there is some evidence, include the activation by DAXX of stress-associated kinases such as the apoptosis signal-regulating kinase ASK-1 [145] or zip kinase [146, 147]. Many aspects of this pathway remain poorly defined, including the implied transfer of DAXX from nucleus to cytoplasm, although several candidate mechanisms have been described [145, 148-150]. Nonetheless, DAXX can have both pro- and antiapoptotic functions, depending on different factors [144]. It has been shown to act as a chromatin modifier through its interaction with HDACs and other proteins involved in epigenetic mechanisms [29, 144]. DAXX is recruited to PML-RAR $\alpha$ through its ability to bind SUMO, and this has been proposed to be required for transformation [151]. In addition, DAXX has been found to promote the Mdm2mediated degradation of $\mathrm{p} 53$, which would support its antiapoptotic function [152]. It would be tempting to speculate that PML could block DAXX-mediated p53 degradation by sequestering DAXX into PML-NDs. These findings suggest that, depending on different partners or localisation patterns, DAXX may exert either tumour-promoting or 
tumour-suppressive functions. Clearly, the field is in need of animal models to test this and other hypotheses.

PML has also been shown to interact with c-Jun upon UV irradiation and to modulate its pro-apoptotic function through c-Jun-N-terminal kinase (JNK)-dependent phosphorylation [83, 153] (Figure 4). JNK activation provokes dramatic PML-ND re-organisation, which leads to the formation of multiple microspeckles positive for both c-Jun and PML [153]. This may be another manifestation of the function of PML-NDs as sensors of DNA damage. Formation of UV-induced microspeckles has been shown to be dependent upon p53, although this has not been confirmed in vivo [82]. Finally, as described above, PML can limit the availability of phosphorylated Akt through its targeting to PML-NDs and its PP2A-dependent dephosphorylation [70] (Figure 4). This in turn results in activation of forkhead transcription factors and the transcription of proapoptotic Bim and the cell cycle inhibitor $\mathrm{p} 27^{\mathrm{kip} 1}$. This connection has functional implications in vivo, as Pml inactivation promotes tumour formation in the prostate in a mouse heterozygous for Pten, which is the major cellular inhibitor of the PI-3K pathway (see below).

\section{Regulation of protein synthesis}

In the last few years several seminal studies have demonstrated that regulation of translation appears to be a crucial step in tumorigenesis $[154,155]$. A number of papers have proposed that PML can regulate translation through its ability to interact with the eukaryotic initiation of translation factor $4 \mathrm{E}$ (eIF4E) [156, 157], which leads to the nuclear retention of eIF4E and inhibition of its role in mRNA export. This results in the sequestration of a number of transcripts involved in cell cycle regulation and a reduced proliferative capacity. In particular, cyclin D1 mRNA has been shown to be one of the major targets of the PML/eIF4E complex [156, 157] (Figure 4).

Another twist in this area of investigation came from a recent paper by the Pandolfi group, which showed that PML regulates translation through its interaction with mTOR [68] (Figure 4). In particular, PML regulates the rate of translation of the hypoxia inducible factor 1 alpha (HIF $1 \alpha$ ) through its ability to alter mTOR function and its localisation to PML-NDs. Consequently, in PML-deficient mice HIF $1 \alpha$ translation is increased, which augments neoangiogenesis and increases tumour vascularisation. As already mentioned, previous work from the same group demonstrated that Akt was inhibited by PML through a PP2A-dependent dephosphorylation [70], which would suggest that this could also inhibit Akt-dependent mTOR activation (Figure 4). However, mTOR inactivation appears to be tuberous sclerosis 2 (TSC2)-independent, indicating that Akt is not a main player in this context [68]. This could be proven by testing whether hyperactivation of mTOR in PML-deficient cells is blocked upon inhibition of Akt. It would also be of interest to determine whether mTOR and Akt are present in the same or different subsets of PMLNDs. Finally, it is not clear whether increased translation of HIF $1 \alpha$ in Pml null cells relies on eIF4E, which is activated by $m$ TOR and inhibited by PML [156], and if PML induces nuclear retention of HIF $1 \alpha$ mRNA. In summary, increasing evidence suggests that PML is involved in the regulation of translation and potentially metabolism through nuclear accumulation of different components of the PI3K/Akt pathway. However, little effort has been made to establish the connections between the different components of this pathway in the context of PML-dependent regulation.

Another way by which PML could regulate cellular metabolism is through its connection with p53. For instance, p53 regulates metabolism and autophagy through its target gene TIGAR $[158,159]$. Therefore, it would be plausible that PML also regulates this novel p53 function.

\section{Genomic stability}

Tumour suppressors can limit tumour progression by controlling genomic stability. PML has been implicated in this cellular function through its ability to target effectors of the DNA damage pathways to PML-NDs or other structures. For instance, the DNA helicase Bloom protein (BLM) localises to the PML-NDs, and PML loss results in increased sister chromatid exchange, which is normally repressed by BLM [160]. It appears that BLM can shuttle between PML-NDs and sites of DNA damage, and that this process is regulated by its SUMOylation [161]. PML also co-localises and interacts with MRE11, which is involved in the regulation of the DNA damage response $[162,163]$. MRE11 is released from PML-NDs upon DNA damage and localises to DNA damage foci, thus suggesting that PML regulates the availability of MRE11 [162]. The impact of PML inactivation on MRE11 function is, however, unclear. PML/MRE11 localisation is also observed in cancer cells that maintain their telomeres by a telomerase-independent 'alternative mechanism' (ALT; see below). Interestingly, two other DNA helicases localise to PML-NDs, Werner (WRN) and RecQL4, which, like BLM, are mutated in human syndromes that display increased genomic instability $[164,165]$. Again, the functional involvement of PML-NDs in processes regulated by these helicases is currently unknown.

Another potential role for PML in the regulation of genomic stability is suggested by the observation that the chromatin-remodelling ATRX protein can localise to PML-NDs [166, 167]. ATRX appears to shuttle between heterochromatin and PML-NDs, and this movement is altered by mutations found in ATR-X patients [168]. Another 
PML-ND component, DAXX, has also been found associated with ATRX, in both PML-NDs and heterochromatic foci ([144] and references cited therein). It is, however, still unclear if and how DAXX and PML can regulate ATRX function.

\section{Anti-viral functions}

A vast literature has detailed the disruption of PML-NDs wrought by virus infection, particularly by the oncogenic DNA viruses [reviewed in depth in reference 168]. Though extensive coverage of this literature is beyond the scope of this review, we should point out that we still have very little idea as to the PML-ND-centric pathways that are activated in order to protect the cell from infection. PML-ND detection of viral ingress [64] and inhibition of viral replication are clearly functions that are countered by several viral proteins and promoted by the interferons. Future work will almost certainly show that viral alterations to PML-ND function serve the virus throughout its lifecycle and that the efficacy of the PML-ND response to other stresses may be titrated by the activities of viral proteins.

\section{A role for PML in cancer}

Most research in the PML field focused for several years on studying the impact of the APL translocation on the function of PML and other PML-ND components. To date, it is not completely clear whether PML inactivation or disruption of PML-NDs is an essential step in the pathogenesis of APL. Moreover, only recently have a number of studies attempted to determine if PML acts as a tumour suppressor in cancers other than APL. In this section, we attempt to critically discuss the available data on the role of PML in tumorigenesis.

$A P L$

One of the open questions in the field of PML and APL research is whether PML inactivation is required for APL leukaemogenesis and to what extent the interaction between PML and PML-RAR $\alpha$ is instrumental for transformation. PML-RAR $\alpha$ homo-oligomerises to form high molecular weight complexes, which are required for transformation both in vitro and in vivo $[9,169,170]$. In addition, PMLRAR $\alpha$ is able to interact with PML ([8] and references cited therein). Loss of PML in a mouse model of APL causes acceleration and increased incidence of the disease, thus suggesting that inactivation of PML is important for disease progression [171]. In contrast, in vitro studies have shown that a PML-RAR $\alpha$ mutant unable to bind PML or disrupt the PML-NDs is capable of transforming haematopoietic cells $[9,169,170]$. Thus, clear differences exist between in vivo and in vitro studies. This is confirmed by the study from Sternsdorf and co-workers [9] that clearly showed that fusing an unrelated homodimerisation domain to RAR $\alpha$ creates a chimaeric protein ( $\mathrm{p} 50-\mathrm{RAR} \alpha$ ) with transforming potential in vitro but not in vivo. This finding indicates that the PML portion of PML-RAR $\alpha$, and its potential to regulate the PML-ND, is required for transformation in vivo. However, loss of PML in cells expressing p50-RAR $\alpha$ does not result in full-blown leukaemia, indicating that combined PML inactivation and RAR $\alpha$ homodimerisation cannot phenocopy the activity of PML-RAR $\alpha$. Given these findings, how does one explain the observation that PML inactivation accelerates PML-RAR $\alpha$-mediated APL progression [172]? One possibility would be that through binding to PML, PML-RAR $\alpha$ could induce growth suppression, and therefore lack of PML would unleash the full transforming potential of PML-RAR. PML-RAR $\alpha$ is growth suppressive in most haemopoietic cell lines, although it is not known if this is dependent on its interaction with PML [173]. On the other hand, it is not clear why PML-RAR would require its PML moiety to induce transformation in vivo, other than for its oligomerisation capacity. One possibility is that PMLRAR $\alpha$, through binding to PML, could hijack a number of PML-ND components required for chromatin remodelling and transcriptional repression. In this fashion PML-RAR $\alpha$ may act both as a dominant negative and gain-of-function mutant. Supporting evidence for this hypothesis is the finding that the PML-ND component DAXX, which is involved with PML in the regulation of cell death, appears to be required for transcriptional repression and (potentially) transformation by PML-RAR $\alpha$ ? [151]. Interestingly, a recent report showed that the $P M L$ gene is found translocated to the Pax5 locus in B-Acute lymphoblastic leukaemia [174]. This is the first report of a translocation involving PML, other than in APL. The main question would be whether similar mechanisms are exploited by this fusion protein to promote transformation. Overall, these findings support the notion that disruption/modification of PML and the PML-ND can be instrumental in disease progression in APL and possibly B-ALL.

As mentioned above, in APL one PML allele is involved in the $\mathrm{t}(15 ; 17)$ translocation of APL, while the other allele is apparently unaffected. However, a recent study has shown that the second $P M L$ allele can also be mutated [175]. The first mutation, Mut1, is a deletion, 1272delAG, in exon 5. The second DNA variant, Mut2, is a splice site mutation that causes a frameshift and splices out exon 4 from the mature transcript. Both mutations produce a stop codon upstream of the NLS. Consequently, the two mutant proteins accumulate in the cytoplasm [175]. It is worth noting that both mutations were associated with very aggressive disease and poor prognosis [175]. A recent paper has also demonstrated that cytoplasmic PML mutants inhibit ATRA- 
dependent degradation of PML-RAR $\alpha$ and potentiate its inhibitory function toward differentiation [176] (reviewed in [14]). PML-RAR $\alpha$ itself localises to the cytoplasm, and a constitutively cytoplasmic form of the fusion protein retains its anti-differentiation properties $[14,176]$. Other studies have shown that forcing PML to the cytoplasm results in nuclear PML-ND disruption [177, 178], and that this negatively affects p53 function and p53-dependent cellular senescence [179]. Overall, these findings suggest that localisation of PML and PML-RAR $\alpha$ to the cytoplasm may contribute to leukaemogenesis. Despite this progress, the mechanisms involved and the description of an innate transforming capacity for cytoplasmic PML-RAR $\alpha$ have yet to be shown.

\section{Non-APL human tumours}

Loss of PML A recent study has employed tissue micro- arrays to analyse PML expression in cancers of multiple histological origins [66]. PML expression appears to be lost or reduced in many different human neoplasms, from haematopoietic tumours to carcinomas: PML expression is lost in $17 \%$ of colon adenocarcinomas, $21 \%$ of lung tumours, $27 \%$ of prostate adenocarcinomas, $31 \%$ of breast adenocarcinomas, $49 \%$ of CNS tumours (100\% medulloblastomas and over $90 \%$ oligodendroglial tumours), $49 \%$ of germ cell tumours and $68 \%$ of non-Hodgkin's lymphomas ( $83 \%$ diffuse large cell lymphomas and 77\% follicular lymphomas). Other studies have shown that PML expression is lost in breast carcinomas [180], gastric cancer [181], small cell lung carcinoma [182] and in invasive epithelial tumours [107]. Another interesting finding of the work by Gurrieri et al. is that loss of PML correlates with higher tumour grading in breast adenocarcinomas, prostate carcinomas and CNS tumours, which confirmed the data from gastric cancers

Table 1 Summary of the in vivo models available to study PML tumour suppressive function

\begin{tabular}{ll}
\hline $\begin{array}{l}\text { In vivo model to study PML } \\
\text { tumour suppressive function }\end{array}$ & Results and principle conclusion \\
\hline$D M B A / T P A-i n d u c e d$ & Skin exposure: increased papilloma/carcinoma incidence \\
carcinogenesis & Salivary gland injection: T/B lymphomas and fibrohistocytomas \\
& Conclusion: PML acts as a tumour suppressor in two models of chemically \\
& induced carcinogenesis
\end{tabular}

APL pathogenesis: PML-RARa

expressed in murine myeloid

progenitors

Tumorigenesis in nude mice: transformed Pml-/- MEFs

injected into nude mice

fibrosarcomas scored

Prostate and colon cancer: reduce PML gene dosage in Pten $+/$ - mice

Lung cancer: Pml null mice were crossed with a doxycycline (DOX)-inducible compound transgenic mutant model of $\mathrm{K}-\mathrm{Ras}^{\mathrm{G} 12 \mathrm{D}}$-induced non-small cell lung cancer (NSCLC)
APL-like disease in mice with long latency and incomplete penetrance.

Reduced $\mathrm{Pml}$ gene dosage decreases latency and increases penetrance. Conclusion: PML plays a tumour suppressive role in a tumour model of APL

Pml-/- MEFs generate larger fibrosarcomas and tumours with greater microvessel density and more haemorrhagic lesions Conclusion: suggests role for PML in angiogenesis

Invasive adenocarcinoma of the colon in Pten $+/-; P m l-/-$ animals. Pml gene dosage-dependent increase in the number and size of polyps. Highly invasive prostate cancers in Pten $+/-; P m l+/-$ and Pten $+/-; P m l-/-$ mice Conclusion: establishes tumour suppressive link for PML in the PI-3K/Akt pathway and supports the notion that $P m l$ is haploinsufficient in cancer development.

Pml-/ - mice have increased tumour burden and more malignant phenotype Conclusion: genetic evidence that loss of PML in the lung plays an important role in NSCLC pathogenesis 
[183]. The only caveat of this work is its dependence on a single anti-PML antibody, the monoclonal PGM3 antibody. PGM3 has been reported to be partially resistant to fixation [180], indicating that low levels of expression could be missed. Nevertheless, western blot analyses of PML expression shows that it is lost in two colon carcinoma cell lines, confirming the data obtained using tissue sections. Despite the lack of expression at the protein level, PML mRNA is normally expressed and no mutations are found in any of the samples analysed [66]. Interestingly, the use of a proteasome inhibitor causes PML re-expression in PMLnegative colon carcinoma and gastric cancer cell lines, suggesting that PML could be actively degraded in cancer cells $[66,183]$. Indeed, the same group demonstrated that PML is degraded by the ubiquitin-proteasome system [93]. Interestingly, PML ubiquitination is controlled by casein kinase 2-dependent phosphorylation, and this mechanism is important for tumorigenesis [93]. However, a PML ubiquitin ligase(s) has not yet been identified. In this respect, it would be interesting to determine whether the expression of a PML ubiquitin ligase(s) inversely correlates with PML expression in cancer.

PML-ND modification Another way by which PML could be altered in cancer is through modifications of its localisation pattern and of PML-ND composition/integrity. A number of studies have shown that PML-NDs are altered in tumour cells that maintain their telomeres by an alternative mechanism (ALT), which is independent of telomerase. ALT tumours represent approximately $15 \%$ of human cancers [184]. A novel PML body is present in $1-5 \%$ of interphase nuclei of ALT-positive cells and not telomerase-positive or normal cells [184]. These structures were termed ALT-associated PML bodies (APBs). The composition of APBs is significantly different from that of PML-NDs. APBs are unique due to the presence of TTAGGG telomeric repeat sequences, telomere binding proteins TRF1 and TRF2, PML and several proteins involved in DNA repair and recombination, such as replication factor A, homologous recombination gene products RAD51 and RAD52, components of the MRN complex and others [184]. In addition, APBs have also been demonstrated to contain proteins found in PML-NDs, such as BLM and Sp100 [184]. It has become evident that these structures are specific to ALT-positive cells, since other cell types examined show no evidence of such aggregates [184]. APBs were also detected in ALT tumour tissues $[64,184]$. APBs have been proposed to play a role in recombinatory mechanisms for telomere elongation in ALT cells [184]. A recent study suggests that APBs are sites of accumulation of single-stranded telomeric DNA originated from telomere processing [185]. However, it is still unclear whether these
ssDNAs are simply stored in APBs or are instead used in the recombination process. What remains to be addressed is the role of PML in ALT cells and telomere elongation. In this regard, a recent report has postulated that PML is involved in transduction of growth arrest signals following alterations of the shelterin complex in ALT cells [186]. Another study has proposed that PML is required for the formation of APBs [187], although the functional implications of its down-regulation have not been determined.

Collectively, these studies suggest a tumour suppressive role for PML in human cancer, which is supported by in vivo data collated from animal models (Table 1). Future work must establish the different levels at which PML regulates tumorigenicity and cell fate selection, as well as the regulators of PML itself.

\section{Concluding remarks}

PML plays a tumour suppressive role in a wider spectrum of human neoplasms than previously thought. In cancer cells its concentration may be down-regulated by the ubiquitin/proteasome system. The fact that PML loss on its own is not sufficient to promote tumour formation probably reflects its role in stress responses and indicates that further changes are needed to promote tumorigenesis. For instance, in animal models PML inactivation cooperates with activation of the PI-3K pathway to promote carcinoma formation in the prostate. Versatile PML function, combined with the complex signalling microenvironment provided by each PML-ND, makes it difficult to predict how different tissues will respond to PML loss and hence its role in different varieties of cancer. The recent work reviewed here has expanded our knowledge of PML and added further layers of complexity to an already intricate field. There still exist major biological questions and technical challenges in the field of PML biology. One significant test in this field will be the development of rigorous biological models for the analysis of the PML/PML-ND proteome following stresses and at different stages of tumorigenesis along with examination of the role of specific PML isoforms in these processes.

\section{References}

1 Melnick A, Licht JD. Deconstructing a disease: RARalpha, its fusion partners, and their roles in the pathogenesis of acute promyelocytic leukemia. Blood 1999; 93:3167-3215.

2 Li YP, Andersen J, Zelent A, et al. RAR alpha1/RAR alpha2PML mRNA expression in acute promyelocytic leukemia cells: a molecular and laboratory-clinical correlative study. Blood 1997; 90:306-312.

3 Brown D, Kogan S, Lagasse E, et al. A PMLRARalpha transgene initiates murine acute promyelocytic leukemia. Proc Natl Acad Sci USA 1997; 94:2551-2556. 
4 Grisolano JL, Wesselschmidt RL, Pelicci PG, Ley TJ. Altered myeloid development and acute leukemia in transgenic mice expressing PML-RAR alpha under control of cathepsin G regulatory sequences. Blood 1997; 89:376-387.

5 He D, Mu ZM, Le X, et al. Adenovirus-mediated expression of PML suppresses growth and tumorigenicity of prostate cancer cells. Cancer Res 1997; 57:1868-1872.

6 Pollock JL, Westervelt P, Kurichety AK, et al. A bcr-3 isoform of RARalpha-PML potentiates the development of PML-RARalpha-driven acute promyelocytic leukemia. Proc Natl Acad Sci USA 1999; 96:15103-15108.

7 Chen JY, Clifford J, Zusi C, et al. Two distinct actions of retinoid-receptor ligands. Nature 1996; 382:819-822.

8 Salomoni P, Pandolfi PP. The role of PML in tumor suppression. Cell 2002; 108:165-170.

9 Sternsdorf T, Phan VT, Maunakea ML, et al. Forced retinoic acid receptor alpha homodimers prime mice for APL-like leukemia. Cancer Cell 2006; 9:81-94.

10 Slack JL, Gallagher RE. The molecular biology of acute promyelocytic leukemia. Cancer Treat Res 1999; 99:75-124.

11 Jensen K, Shiels C, Freemont PS. PML protein isoforms and the RBCC/TRIM motif. Oncogene 2001; 20:7223-7233.

12 Nisole S, Stoye JP, Saib A. TRIM family proteins: retroviral restriction and antiviral defence. Nat Rev Microbiol 2005; 3:799-808.

13 Fagioli M, Alcalay M, Pandolfi PP, et al. Alternative splicing of PML transcripts predicts coexpression of several carboxyterminally different protein isoforms. Oncogene 1992; 7:10831091.

14 Salomoni P, Bellodi C. New insights into the cytoplasmic function of PML. Histol Histopathol 2007; 22:937-946.

15 Reymond A, Meroni G, Fantozzi A, et al. The tripartite motif family identifies cell compartments. EMBO J 2001; 20:21402151.

16 Joazeiro CA, Weissman AM. RING finger proteins: mediators of ubiquitin ligase activity. Cell 2000; 102:549-552.

17 Meroni G, Diez-Roux G. TRIM/RBCC, a novel class of 'single protein RING finger' E3 ubiquitin ligases. BioEssays 2005; 27:1147-1157.

18 Burkhard P, Stetefeld J, Strelkov SV. Coiled coils: a highly versatile protein folding motif. Trends Cell Biol 2001; 11:82-88.

19 Massiah MA, Simmons BN, Short KM, Cox TC. Solution structure of the RBCC/TRIM B-box 1 domain of human MID1: B-box with a RING. J Mol Biol 2006; 358:532-545.

20 Cao T, Borden KL, Freemont PS, Etkin LD. Involvement of the rfp tripartite motif in protein-protein interactions and subcellular distribution. J Cell Sci 1997; 110(Part 14):1563-1571.

21 Peng H, Begg GE, Schultz DC, et al. Reconstitution of the KRAB-KAP-1 repressor complex: a model system for defining the molecular anatomy of RING-B box-coiled-coil domain-mediated protein-protein interactions. J Mol Biol 2000; 295:11391162.

22 Borden KL, Lally JM, Martin SR, et al. In vivo and in vitro characterization of the B1 and B2 zinc-binding domains from the acute promyelocytic leukemia protooncoprotein PML. Proc Natl Acad Sci USA 1996; 93:1601-1606.

23 Fagioli M, Alcalay M, Tomassoni L, et al. Cooperation between the RING + B1-B2 and coiled-coil domains of PML is necessary for its effects on cell survival. Oncogene 1998; 16:2905-2913.
24 Borden KL, Boddy MN, Lally J, et al. The solution structure of the RING finger domain from the acute promyelocytic leukaemia proto-oncoprotein PML. EMBO J 1995; 14:1532-1541.

25 Kastner P, Perez A, Lutz Y, et al. Structure, localization and transcriptional properties of two classes of retinoic acid receptor alpha fusion proteins in acute promyelocytic leukemia (APL): structural similarities with a new family of oncoproteins. EMBO J 1992; 11:629-642.

26 Kamitani T, Kito K, Nguyen HP, et al. Identification of three major sentrinization sites in PML. J Biol Chem 1998; 273:2667526682.

27 Shen TH, Lin HK, Scaglioni PP, Yung TM, Pandolfi PP. The mechanisms of PML-nuclear body formation. Mol Cell 2006; 24:331-339.

28 Ishov AM, Sotnikov AG, Negorev D, et al. PML is critical for ND10 formation and recruits the PML-interacting protein daxx to this nuclear structure when modified by SUMO-1. J Cell Biol 1999; 147:221-234.

29 Lin DY, Huang YS, Jeng JC, et al. Role of SUMO-interacting motif in Daxx SUMO modification, subnuclear localization, and repression of sumoylated transcription factors. Mol Cell 2006; 24:341-354.

30 Quimby BB, Yong-Gonzalez V, Anan T, Strunnikov AV, Dasso M. The promyelocytic leukemia protein stimulates SUMO conjugation in yeast. Oncogene 2006; 25:2999-3005.

31 Duprez E, Saurin AJ, Desterro JM, et al. SUMO-1 modification of the acute promyelocytic leukaemia protein PML: implications for nuclear localisation. J Cell Sci 1999; 112(Part 3):381-393.

32 Mukhopadhyay D, Ayaydin F, Kolli N, et al. SUSP1 antagonizes formation of highly SUMO2/3-conjugated species. J Cell Biol 2006; 174:939-949.

33 Best JL, Ganiatsas S, Agarwal S, et al. SUMO-1 protease-1 regulates gene transcription through PML. Mol Cell 2002; 10:843-855.

34 Hay RT. SUMO: a history of modification. Mol Cell 2005; 18:112.

35 Heun P. SUMOrganization of the nucleus. Curr Opin Cell Biol 2007; 19:350-355.

36 Vertegaal AC, Andersen JS, Ogg SC, et al. Distinct and overlapping sets of SUMO-1 and SUMO-2 target proteins revealed by quantitative proteomics. Mol Cell Proteomics 2006; 5:22982310.

37 Fu C, Ahmed K, Ding H, et al. Stabilization of PML nuclear localization by conjugation and oligomerization of SUMO-3. Oncogene 2005; 24:5401-5413.

38 Tatham MH, Kim S, Jaffray E, et al. Unique binding interactions among Ubc9, SUMO and RanBP2 reveal a mechanism for SUMO paralog selection. Nat Struct Mol Biol 2005; 12:6774.

39 Saitoh H, Hinchey J. Functional heterogeneity of small ubiquitin-related protein modifiers SUMO-1 versus SUMO-2/3. J Biol Chem 2000; 275:6252-6258.

40 Boe SO, Haave M, Jul-Larsen A, et al. Promyelocytic leukemia nuclear bodies are predetermined processing sites for damaged DNA. J Cell Sci 2006; 119:3284-3295.

41 Luciani JJ, Depetris D, Usson Y, et al. PML nuclear bodies are highly organised DNA-protein structures with a function in heterochromatin remodelling at the G2 phase. J Cell Sci 2006; 119:2518-2531. 
42 Aoto T, Saitoh N, Ichimura T, Niwa H, Nakao M. Nuclear and chromatin reorganization in the MHC-Oct3/4 locus at developmental phases of embryonic stem cell differentiation. Dev Biol 2006; 298:354-367.

43 Wang J, Shiels C, Sasieni P, et al. Promyelocytic leukemia nuclear bodies associate with transcriptionally active genomic regions. J Cell Biol 2004; 164:515-526.

44 Luciani JJ, Depetris D, Missirian C, et al. Subcellular distribution of HP1 proteins is altered in ICF syndrome. Eur J Hum Genet 2005; 13:41-51.

45 Kumar PP, Bischof O, Purbey PK, et al. Functional interaction between PML and SATB1 regulates chromatin-loop architecture and transcription of the MHC class I locus. Nat Cell Biol 2007; 9:45-56.

46 Bishop CL, Ramalho M, Nadkarni N, et al. Role for centromeric heterochromatin and PML nuclear bodies in the cellular response to foreign DNA. Mol Cell Biol 2006; 26:2583-2594.

47 Block GJ, Eskiw CH, Dellaire G, Bazett-Jones DP. Transcriptional regulation is affected by subnuclear targeting of reporter plasmids to PML nuclear bodies. Mol Cell Biol 2006; 26:88148825.

48 Condemine W, Takahashi Y, Zhu J, et al. Characterization of endogenous human promyelocytic leukemia isoforms. Cancer Res 2006; 66:6192-6198.

49 Rangarajan A, Weinberg RA. Opinion: Comparative biology of mouse versus human cells: modelling human cancer in mice. Nat Rev Cancer 2003; 3:952-959.

50 Shiels C, Islam SA, Vatcheva R, et al. PML bodies associate specifically with the MHC gene cluster in interphase nuclei. $J$ Cell Sci 2001; 114:3705-3716.

51 Dunker AK, Cortese MS, Romero P, Iakoucheva LM, Uversky VN. Flexible nets. The roles of intrinsic disorder in protein interaction networks. FEBS J 2005; 272:5129-5148.

52 Hoppe A, Beech SJ, Dimmock J, Leppard KN. Interaction of the adenovirus type $5 \mathrm{E} 4$ Orf3 protein with promyelocytic leukemia protein isoform II is required for ND10 disruption. J Virol 2006; 80:3042-3049.

53 Fogal V, Gostissa M, Sandy P, et al. Regulation of p53 activity in nuclear bodies by a specific PML isoform. EMBO J 2000; 19:6185-6195.

54 Guo A, Salomoni P, Luo J, et al. The function of PML in p53dependent apoptosis. Nat Cell Biol 2000; 2:730-736.

55 Alcalay M, Tomassoni L, Colombo E, et al. The promyelocytic leukemia gene product (PML) forms stable complexes with the retinoblastoma protein. Mol Cell Biol 1998; 18:1084-1093.

56 Wu WS, Vallian S, Seto E, et al. The growth suppressor PML represses transcription by functionally and physically interacting with histone deacetylases. Mol Cell Biol 2001; 21:2259-2268.

57 Bischof O, Kirsh O, Pearson M, et al. Deconstructing PMLinduced premature senescence. EMBO J 2002; 21:3358-3369.

58 Condemine W, Takahashi Y, Le Bras M, de The H. A nucleolar targeting signal in PML-I addresses PML to nucleolar caps in stressed or senescent cells. J Cell Sci 2007; 120:3219-3227.

59 Lin HK, Bergmann S, Pandolfi PP. Cytoplasmic PML function in TGF-beta signalling. Nature 2004; 431:205-211.

$60 \mathrm{Li} \mathrm{H}$, Leo C, Zhu J, et al. Sequestration and inhibition of Daxxmediated transcriptional repression by PML. Mol Cell Biol 2000; 20:1784-1796.

61 Yang S, Jeong JH, Brown AL, et al. Promyelocytic leukemia activates Chk2 by mediating Chk2 autophosphorylation. J Biol Chem 2006; 281:26645-26654.

62 Yang S, Kuo C, Bisi JE, Kim MK. PML-dependent apoptosis after DNA damage is regulated by the checkpoint kinase hCds1/ Chk2. Nat Cell Biol 2002; 4:865-870.

$63 \mathrm{Wu}$ G, Lee WH, Chen PL. NBS1 and TRF1 colocalize at promyelocytic leukemia bodies during late $\mathrm{S} / \mathrm{G} 2$ phases in immortalized telomerase-negative cells. Implication of NBS1 in alternative lengthening of telomeres. J Biol Chem 2000; 275:30618-30622.

64 Yeager TR, Neumann AA, Englezou A, et al. Telomerase-negative immortalized human cells contain a novel type of promyelocytic leukemia (PML) body. Cancer Res 1999; 59:4175-4179.

65 Everett RD, Murray J, Orr A, Preston CM. Herpes simplex virus type 1 genomes are associated with ND10 nuclear substructures in quiescently infected human fibroblasts. $J$ Virol 2007; 81:10991-11004.

66 Gurrieri C, Capodieci P, Bernardi R, et al. Loss of the tumor suppressor PML in human cancers of multiple histologic origins. J Natl Cancer Inst 2004; 96:269-279.

67 Dellaire G, Bazett-Jones DP. PML nuclear bodies: dynamic sensors of DNA damage and cellular stress. BioEssays 2004; 26:963-977.

68 Bernardi R, Guernah I, Jin D, et al. PML inhibits HIF-1alpha translation and neoangiogenesis through repression of mTOR. Nature 2006; 442:779-785.

69 Ferguson BJ, Dovey CL, Lilley K, Wyllie AH, Rich T. Nuclear phospholipase $\mathrm{C}$ gamma: punctate distribution and association with the promyelocytic leukemia protein. J Proteome Res 2007; 6:2027-2032.

70 Trotman LC, Alimonti A, Scaglioni PP, et al. Identification of a tumour suppressor network opposing nuclear Akt function. Nature 2006; 441:523-527.

71 Beech SJ, Lethbridge KJ, Killick N, McGlincy N, Leppard KN. Isoforms of the promyelocytic leukemia protein differ in their effects on ND10 organization. Exp Cell Res 2005; 307:109-117.

72 Varadaraj A, Dovey CL, Laredj L, et al. Evidence for the receipt of DNA damage stimuli by PML nuclear domains. J Pathol 2007; 211:471-480.

73 Minton AP. Macromolecular crowding. Curr Biol 2006; 16: R269-271.

74 Martelli AM, Cocco L, Capitani S, et al. Nuclear phosphatidylinositol 3,4,5-trisphosphate, phosphatidylinositol 3-kinase, Akt, and PTen: emerging key regulators of anti-apoptotic signaling and carcinogenesis. Eur J Histochem 2007; 51(Suppl 1):125-131.

75 Pearson M, Carbone R, Sebastiani C, et al. PML regulates p53 acetylation and premature senescence induced by oncogenic Ras. Nature 2000; 406:207-210.

76 Lafarga M, Berciano MT, Pena E, et al. Clastosome: a subtype of nuclear body enriched in 19S and 20S proteasomes, ubiquitin, and protein substrates of proteasome. Mol Biol Cell 2002; 13:2771-2782.

77 Dellaire G, Ching RW, Ahmed K, et al. Promyelocytic leukemia nuclear bodies behave as DNA damage sensors whose response to DNA double-strand breaks is regulated by NBS1 and the kinases ATM, Chk2, and ATR. J Cell Biol 2006; 175:55-66.

78 Bernardi R, Scaglioni PP, Bergmann S, et al. PML regulates p53 stability by sequestering Mdm2 to the nucleolus. Nat Cell 
Biol 2004; 6:665-672.

79 Tang J, Xie W, Yang X. Association of caspase-2 with the promyelocytic leukemia protein nuclear bodies. Cancer Biol Ther 2005; 4:645-649.

80 Sanchez-Pulido L, Valencia A, Rojas AM. Are promyelocytic leukaemia protein nuclear bodies a scaffold for caspase-2 programmed cell death? Trends Biochem Sci 2007; 32:400-406.

81 Ferguson BJ, Alexander CE, Rossi SW, et al. AIRE's card revealed; a new structure for central tolerance provokes transcriptional plasticity. J Biol Chem 2008; 283:1723-1731.

82 Seker H, Rubbi C, Linke SP, et al. UV-C-induced DNA damage leads to p53-dependent nuclear trafficking of PML. Oncogene 2003; 22:1620-1628.

83 Seo SR, Ferrand N, Faresse N, et al. Nuclear retention of the tumor suppressor cPML by the homeodomain protein TGIF restricts TGF-beta signaling. Mol Cell 2006; 23:547-559.

84 Nefkens I, Negorev DG, Ishov AM, et al. Heat shock and Cd2+ exposure regulate PML and Daxx release from ND10 by independent mechanisms that modify the induction of heat-shock proteins 70 and 25 differently. J Cell Sci 2003; 116:513-524.

85 Regad T, Chelbi-Alix MK. Role and fate of PML nuclear bodies in response to interferon and viral infections. Oncogene 2001; 20:7274-7286.

86 Laredj LN, Ferguson BJ, Rich T. Microbial and acute phase stimuli disrupt promyelocytic leukemia tumor suppressive nodes. Mol Immunol 2008; 45:1477-1484.

87 Everett RD, Murray J. ND10 components relocate to sites associated with herpes simplex virus type 1 nucleoprotein complexes during virus infection. $J$ Virol 2005; 79:5078-5089.

88 Janer A, Martin E, Muriel MP, et al. PML clastosomes prevent nuclear accumulation of mutant ataxin-7 and other polyglutamine proteins. J Cell Biol 2006; 174:65-76.

89 Takahashi J, Fujigasaki H, Zander C, et al. Two populations of neuronal intranuclear inclusions in SCA7 differ in size and promyelocytic leukaemia protein content. Brain 2002; 125:15341543.

90 Dovey CL, Varadaraj A, Wyllie AH, Rich T. Stress responses of PML nuclear domains are ablated by ataxin-1 and other nucleoprotein inclusions. J Pathol 2004; 203:877-883.

91 Jiang WQ, Ringertz N. Altered distribution of the promyelocytic leukemia-associated protein is associated with cellular senescence. Cell Growth Differ 1997; 8:513-522.

92 Janderova-Rossmeislova L, Novakova Z, Vlasakova J, et al. PML protein association with specific nucleolar structures differs in normal, tumor and senescent human cells. J Struct Biol 2007; 159:56-70.

93 Scaglioni PP, Yung TM, Cai LF, et al. A CK2-dependent mechanism for degradation of the PML tumor suppressor. Cell 2006; 126:269-283.

94 Mattsson K, Pokrovskaja K, Kiss C, Klein G, Szekely L. Proteins associated with the promyelocytic leukemia gene product (PML)-containing nuclear body move to the nucleolus upon inhibition of proteasome-dependent protein degradation. Proc Natl Acad Sci USA 2001; 98:1012-1017.

95 Boisvert FM, van Koningsbruggen S, Navascues J, Lamond AI. The multifunctional nucleolus. Nat Rev Mol Cell Biol 2007; 8:574-585.

96 Tembe V, Henderson BR. Protein trafficking in response to DNA damage. Cell Signal 2007; 19:1113-1120.
97 Pederson T. Half a century of "the nuclear matrix". Mol Biol Cell 2000; 11:799-805.

98 Zink D, Fischer AH, Nickerson JA. Nuclear structure in cancer cells. Nat Rev Cancer 2004; 4:677-687.

99 Wiesmeijer K, Molenaar C, Bekeer IM, Tanke HJ, Dirks RW. Mobile foci of Sp100 do not contain PML: PML bodies are immobile but PML and Sp100 proteins are not. J Struct Biol 2002; 140:180-188.

100 Rich T, Varadaraj A. Ataxin-1 fusion partners alter PolyQ lethality and aggregation. PLOS ONE 2007; 2:e1014.

101 Stratford FL, Chondrogianni N, Trougakos IP, Gonos ES, Rivett AJ. Proteasome response to interferon-gamma is altered in senescent human fibroblasts. FEBS Lett 2006; 580:3989-3994.

102 Campbell EM, Dodding MP, Yap MW, et al. TRIM5 alpha cytoplasmic bodies are highly dynamic structures. Mol Biol Cell 2007; 18:2102-2111.

$103 \mathrm{Xu}$ ZX, Zou WX, Lin P, Chang KS. A role for PML3 in centrosome duplication and genome stability. Mol Cell 2005; 17:721732.

104 Katayama H, Sasai K, Kawai H, et al. Phosphorylation by aurora kinase A induces Mdm2-mediated destabilization and inhibition of p53. Nat Genet 2004; 36:55-62.

105 Dellaire G, Ching RW, Dehghani H, Ren Y, Bazett-Jones DP. The number of PML nuclear bodies increases in early $\mathrm{S}$ phase by a fission mechanism. J Cell Sci 2006; 119:1026-1033.

106 Everett RD, Earnshaw WC, Pluta AF, et al. A dynamic connection between centromeres and ND10 proteins. J Cell Sci 1999; 112(Part 20):3443-3454.

107 Koken MH, Linares-Cruz G, Quignon F, et al. The PML growthsuppressor has an altered expression in human oncogenesis. Oncogene 1995; 10:1315-1324.

108 Terris B, Baldin V, Dubois S, et al. PML nuclear bodies are general targets for inflammation and cell proliferation. Cancer Res 1995; 55:1590-1597.

109 Dellaire G, Eskiw CH, Dehghani H, Ching RW, Bazett-Jones DP. Mitotic accumulations of PML protein contribute to the re-establishment of PML nuclear bodies in G1. J Cell Sci 2006; 119:1034-1042.

110 Bartkova J, Rezaei N, Liontos M, et al. Oncogene-induced senescence is part of the tumorigenesis barrier imposed by DNA damage checkpoints. Nature 2006; 444:633-637.

111 Mallette FA, Gaumont-Leclerc MF, Ferbeyre G. The DNA damage signaling pathway is a critical mediator of oncogene-induced senescence. Genes Dev 2007; 21:43-48.

112 Campisi J, d'Adda di Fagagna F. Cellular senescence: when bad things happen to good cells. Nat Rev Mol Cell Biol 2007; 8:729-740.

113 Serrano M, Lin AW, McCurrach ME, Beach D, Lowe SW. Oncogenic ras provokes premature cell senescence associated with accumulation of p53 and p16INK4a. Cell 1997; 88:593-602.

114 He LZ, Tribioli C, Rivi R, et al. Acute leukemia with promyelocytic features in PML/RARalpha transgenic mice. Proc Natl Acad Sci USA 1997; 94:5302-5307.

115 Le XF, Yang P, Chang KS. Analysis of the growth and transformation suppressor domains of promyelocytic leukemia gene, PML. J Biol Chem 1996; 271:130-135.

$116 \mathrm{Mu}$ ZM, Le XF, Vallian S, Glassman AB, Chang KS. Stable overexpression of PML alters regulation of cell cycle progression in HeLa cells. Carcinogenesis 1997; 18:2063-2069. 
117 Le XF, Vallian S, Mu ZM, Hung MC, Chang KS. Recombinant PML adenovirus suppresses growth and tumorigenicity of human breast cancer cells by inducing G1 cell cycle arrest and apoptosis. Oncogene 1998; 16:1839-1849.

118 Ferbeyre G, de Stanchina E, Querido E, et al. PML is induced by oncogenic ras and promotes premature senescence. Genes Dev 2000; 14:2015-2027.

119 Khan MM, Nomura T, Kim H, et al. PML-RARalpha alleviates the transcriptional repression mediated by tumor suppressor $\mathrm{Rb}$. $J$ Biol Chem 2001; 276:43491-43494.

120 Mallette FA, Goumard S, Gaumont-Leclerc MF, Moiseeva O, Ferbeyre G. Human fibroblasts require the Rb family of tumor suppressors, but not p53, for PML-induced senescence. Oncogene 2004; 23:91-99.

121 Wang ZG, Delva L, Gaboli M, et al. Role of PML in cell growth and the retinoic acid pathway. Science 1998; 279:1547-1551.

122 Zhong S, Delva L, Rachez C, et al. A RA-dependent, tumourgrowth suppressive transcription complex is the target of the PML-RARalpha and T18 oncoproteins. Nat Genet 1999; 23:287295.

123 Insinga A, Monestiroli S, Ronzoni S, et al. Impairment of p53 acetylation, stability and function by an oncogenic transcription factor. $E M B O J$ 2004; 23:1144-1154.

124 Chan JY, Li L, Fan YH, et al. Cell-cycle regulation of DNA damage-induced expression of the suppressor gene PML. Biochem Biophys Res Commun 1997; 240:640-646.

125 de Stanchina E, Querido E, Narita M, et al. PML is a direct p53 target that modulates p53 effector functions. Mol Cell 2004; 13:523-535.

126 Labbaye C, Valtieri M, Grignani F, et al. Expression and role of PML gene in normal adult hematopoiesis: functional interaction between PML and $\mathrm{Rb}$ proteins in erythropoiesis. Oncogene 1999; 18:3529-3540.

127 Ye X, Zerlanko B, Zhang R, et al. Definition of pRB- and p53dependent and -independent steps in HIRA/ASF1a-mediated formation of senescence-associated heterochromatin foci. $\mathrm{Mol}$ Cell Biol 2007; 27:2452-2465.

128 Zhang R, Poustovoitov MV, Ye X, et al. Formation of MacroH2A-containing senescence-associated heterochromatin foci and senescence driven by ASF1a and HIRA. Dev Cell 2005; 8:19-30.

129 Ye X, Zerlanko B, Kennedy A, et al. Downregulation of Wnt signaling is a trigger for formation of facultative heterochromatin and onset of cell senescence in primary human cells. Mol Cell 2007; 27:183-196.

130 Narita M, Nunez S, Heard E, et al. Rb-mediated heterochromatin formation and silencing of E2F target genes during cellular senescence. Cell 2003; 113:703-716.

131 Zhang R, Chen W, Adams PD. Molecular dissection of formation of senescence-associated heterochromatin foci. Mol Cell Biol 2007; 27:2343-2358.

132 Quignon F, De Bels F, Koken M, et al. PML induces a novel caspase-independent death process. Nat Genet 1998; 20:259265.

133 Lowe SW, Schmitt EM, Smith SW, Osborne BA, Jacks T. p53 is required for radiation-induced apoptosis in mouse thymocytes. Nature 1993; 362:847-849.

134 Clarke AR, Purdie CA, Harrison DJ, et al. Thymocyte apoptosis induced by $\mathrm{p} 53$-dependent and independent pathways. Nature
1993; 362:849-852.

135 Wang ZG, Ruggero D, Ronchetti S, et al. PML is essential for multiple apoptotic pathways. Nat Genet 1998; 20:266-272.

136 Haupt S, Louria-Hayon I, Haupt Y. P53 licensed to kill? Operating the assassin. $J$ Cell Biochem 2003; 88:76-82.

137 Kurki S, Latonen L, Laiho M. Cellular stress and DNA damage invoke temporally distinct Mdm2, p53 and PML complexes and damage-specific nuclear relocalization. J Cell Sci 2003; 116:3917-3925.

138 Louria-Hayon I, Grossman T, Sionov RV, et al. The promyelocytic leukemia protein protects $\mathrm{p} 53$ from Mdm2-mediated inhibition and degradation. J Biol Chem 2003; 278:33134-33141.

139 Wei X, Yu ZK, Ramalingam A, et al. Physical and functional interactions between PML and MDM2. J Biol Chem 2003; 278:29288-29297.

140 Zhu H, Wu L, Maki CG. MDM2 and promyelocytic leukemia antagonize each other through their direct interaction with p53. J Biol Chem 2003; 278:49286-49292.

141 Chang HY, Nishitoh H, Yang X, Ichijo H, Baltimore D. Activation of apoptosis signal-regulating kinase 1 (ASK1) by the adapter protein Daxx. Science 1998; 281:1860-1863.

142 Salomoni P, Guernah I, Pandolfi PP. The PML-nuclear body associated protein Daxx regulates the cellular response to CD40. Cell Death Differ 2006; 13:672-675.

143 Yang X, Khosravi-Far R, Chang HY, Baltimore D. Daxx, a novel Fas-binding protein that activates JNK and apoptosis. Cell 1997; 89:1067-1076.

144 Salomoni P, Khelifi AF. Daxx: death or survival protein? Trends Cell Biol 2006; 16:97-104.

145 Junn E, Taniguchi H, Jeong BS, et al. Interaction of DJ-1 with Daxx inhibits apoptosis signal-regulating kinase 1 activity and cell death. Proc Natl Acad Sci USA 2005; 102:9691-9696.

146 Kawai T, Akira S, Reed JC. ZIP kinase triggers apoptosis from nuclear PML oncogenic domains. Mol Cell Biol 2003; 23:61746186.

147 Shani G, Marash L, Gozuacik D, et al. Death-associated protein kinase phosphorylates ZIP kinase, forming a unique kinase hierarchy to activate its cell death functions. Mol Cell Biol 2004; 24:8611-8626.

148 Kitagawa D, Kajiho H, Negishi T, et al. Release of RASSF1C from the nucleus by Daxx degradation links DNA damage and SAPK/JNK activation. EMBO J 2006; 25:3286-3297.

149 Boehrer S, Nowak D, Hochmuth S, et al. Daxx overexpression in T-lymphoblastic Jurkat cells enhances caspase-dependent death receptor- and drug-induced apoptosis in distinct ways. Cell Signal 2005; 17:581-595.

150 Li Q, Wang X, Wu X, et al. Daxx cooperates with the Axin/ HIPK2/p53 complex to induce cell death. Cancer Res 2007; 67:66-74.

151 Zhu J, Zhou J, Peres L, et al. A sumoylation site in PML/RARA is essential for leukemic transformation. Cancer Cell 2005; 7:143-153.

152 Tang J, Qu LK, Zhang J, et al. Critical role for Daxx in regulating Mdm2. Nat Cell Biol 2006; 8:855-862.

153 Salomoni P, Bernardi R, Bergmann S, et al. The promyelocytic leukemia protein PML regulates c-Jun function in response to DNA damage. Blood 2005; 105:3686-3690.

154 Ruggero D, Pandolfi PP. Does the ribosome translate cancer? Nat Rev Cancer 2003; 3:179-192. 
155 Yoon A, Peng G, Brandenburger Y, et al. Impaired control of IRES-mediated translation in X-linked dyskeratosis congenita. Science 2006; 312:902-906.

156 Cohen N, Sharma M, Kentsis A, et al. PML RING suppresses oncogenic transformation by reducing the affinity of eIF4E for mRNA. EMBO J 2001; 20:4547-4559.

157 Culjkovic B, Topisirovic I, Borden KL. Controlling gene expression through RNA regulons: the role of the eukaryotic translation initiation factor eIF4E. Cell Cycle 2007; 6:65-69.

158 Bensaad K, Tsuruta A, Selak MA, et al. TIGAR, a p53-inducible regulator of glycolysis and apoptosis. Cell 2006; 126:107120.

159 Crighton D, Wilkinson S, O'Prey J, et al. DRAM, a p53-induced modulator of autophagy, is critical for apoptosis. Cell 2006; 126:121-134

160 Zhong S, Hu P, Ye TZ, et al. A role for PML and the nuclear body in genomic stability. Oncogene 1999; 18:7941-7947.

161 Eladad S, Ye TZ, Hu P, et al. Intra-nuclear trafficking of the BLM helicase to DNA damage-induced foci is regulated by SUMO modification. Hum Mol Genet 2005; 14:1351-1365.

162 Carbone R, Pearson M, Minucci S, Pelicci PG. PML NBs associate with the hMre 11 complex and p53 at sites of irradiation induced DNA damage. Oncogene 2002; 21:1633-1640.

163 Lombard DB, Guarente L. Nijmegen breakage syndrome disease protein and MRE11 at PML nuclear bodies and meiotic telomeres. Cancer Res 2000; 60:2331-2334.

164 Blander G, Zalle N, Daniely Y, et al. DNA damage-induced translocation of the Werner helicase is regulated by acetylation. $J$ Biol Chem 2002; 277:50934-50940.

165 Petkovic M, Dietschy T, Freire R, Jiao R, Stagljar I. The human Rothmund-Thomson syndrome gene product, RECQL4, localizes to distinct nuclear foci that coincide with proteins involved in the maintenance of genome stability. $J$ Cell Sci 2005; 118:4261-4269.

166 Garrick D, Samara V, McDowell TL, et al. A conserved truncated isoform of the ATR-X syndrome protein lacking the SWI/SNFhomology domain. Gene 2004; 326:23-34.

167 Ishov AM, Vladimirova OV, Maul GG. Heterochromatin and ND10 are cell-cycle regulated and phosphorylation-dependent alternate nuclear sites of the transcription repressor Daxx and SWI/SNF protein ATRX. J Cell Sci 2004; 117:3807-3820.

168 Berube NG, Healy J, Medina CF, et al. Patient mutations alter ATRX targeting to PML nuclear bodies. Eur J Hum Genet 2008; 16:192-201

169 Lin RJ, Evans RM. Acquisition of oncogenic potential by RAR chimeras in acute promyelocytic leukemia through formation of homodimers. Mol Cell 2000; 5:821-830.

170 Minucci S, Maccarana M, Cioce M, et al. Oligomerization of RAR and AML1 transcription factors as a novel mechanism of oncogenic activation. Mol Cell 2000; 5:811-820.

171 Rego EM, Pandolfi PP. Analysis of the molecular genetics of acute promyelocytic leukemia in mouse models. Semin Hematol 2001; 38:54-70.
172 Rego EM, Wang ZG, Peruzzi D, et al. Role of promyelocytic leukemia (PML) protein in tumor suppression. J Exp Med 2001; 193:521-529.

173 Ferrucci PF, Grignani F, Pearson M, et al. Cell death induction by the acute promyelocytic leukemia-specific PML/RARalpha fusion protein. Proc Natl Acad Sci USA 1997; 94:10901-10906.

174 Nebral K, Konig M, Harder L, et al. Identification of PML as novel PAX5 fusion partner in childhood acute lymphoblastic leukaemia. Br J Haematol 2007; 139:269-274.

175 Gurrieri C, Nafa K, Merghoub T, et al. Mutations of the PML tumor suppressor gene in acute promyelocytic leukemia. Blood 2004; 103:2358-2362.

176 Bellodi C, Kindle K, Bernassola F, et al. Cytoplasmic function of mutant promyelocytic leukemia (PML) and PML-retinoic acid receptor-alpha. J Biol Chem 2006; 281:14465-14473.

177 Zheng P, Guo Y, Niu Q, et al. Proto-oncogene PML controls genes devoted to MHC class I antigen presentation. Nature 1998; 396:373-376.

178 Bruno S, Ghiotto F, Fais F, et al. The PML gene is not involved in the regulation of MHC class I expression in human cell lines. Blood 2003; 101:3514-3519.

179 Bellodi C, Kindle K, Bernassola F, et al. A cytoplasmic PML mutant inhibits p53 function. Cell Cycle 2006; 5:2688-2692.

180 Gambacorta M, Flenghi L, Fagioli M, et al. Heterogeneous nuclear expression of the promyelocytic leukemia (PML) protein in normal and neoplastic human tissues. Am J Pathol 1996; 149:2023-2035.

181 Lee HE, Jee CD, Kim MA, et al. Loss of promyelocytic leukemia protein in human gastric cancers. Cancer Lett 2007; 247:103109.

182 Zhang P, Chin W, Chow LT, et al. Lack of expression for the suppressor PML in human small cell lung carcinoma. Int $J$ Cancer 2000; 85:599-605.

183 Paul RH, Laidlaw DH, Tate DF, et al. Neuropsychological and neuroimaging outcome of HIV-associated progressive multifocal leukoencephalopathy in the era of antiretroviral therapy. $J$ Integr Neurosci 2007; 6:191-203.

184 Muntoni A, Reddel RR. The first molecular details of ALT in human tumor cells. Hum Mol Genet 2005; 14Spec No. 2:R191196.

185 Fasching CL, Neumann AA, Muntoni A, Yeager TR, Reddel RR. DNA damage induces alternative lengthening of telomeres (ALT) associated promyelocytic leukemia bodies that preferentially associate with linear telomeric DNA. Cancer Res 2007; 67:7072-7077.

186 Stagno D’Alcontres M, Mendez-Bermudez A, Foxon JL, Royle NJ, Salomoni P. Lack of TRF2 in ALT cells causes PML-dependent p53 activation and loss of telomeric DNA. J Cell Biol 2007; 179:855-867.

187 Jiang WQ, Zhong ZH, Henson JD, Reddel RR. Identification of candidate alternative lengthening of telomeres genes by methionine restriction and RNA interference. Oncogene 2007; 26:4635-4647. 